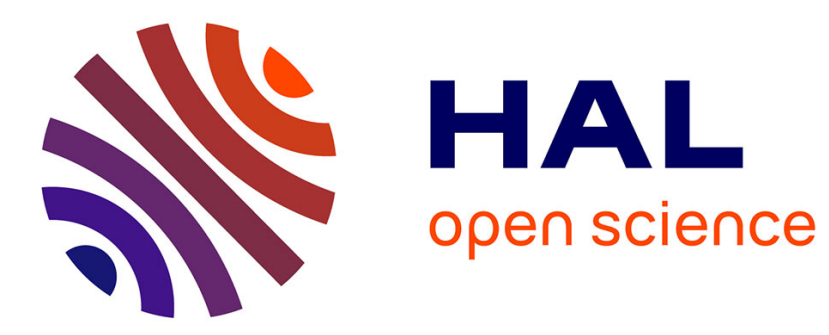

\title{
Hoarding and short-squeezing in times of crisis: Evidence from the Euro overnight money market
}

Olivier Brossard, Susanna Saroyan

\section{To cite this version:}

Olivier Brossard, Susanna Saroyan. Hoarding and short-squeezing in times of crisis: Evidence from the Euro overnight money market. Journal of International Financial Markets, Institutions and Money, 2016, 40, pp.163-185. 10.1016/j.intfin.2015.09.002 . hal-01293693

\section{HAL Id: hal-01293693 https://hal.science/hal-01293693}

Submitted on 25 Mar 2016

HAL is a multi-disciplinary open access archive for the deposit and dissemination of scientific research documents, whether they are published or not. The documents may come from teaching and research institutions in France or abroad, or from public or private research centers.
L'archive ouverte pluridisciplinaire HAL, est destinée au dépôt et à la diffusion de documents scientifiques de niveau recherche, publiés ou non, émanant des établissements d'enseignement et de recherche français ou étrangers, des laboratoires publics ou privés. 


\title{
Hoarding and short-squeezing in times of crisis: evidence from the Euro overnight money market
}

\author{
(PREPRINT: final version published in the Journal of International Financial Markets, \\ Institutions and Money, 40(2016), 163-185)
}

\author{
Olivier Brossard*, Susanna Saroyan** \\ *University of Toulouse; Political Studies Institute, Economics department (LEREPS), Manufacture des \\ Tabacs, 21 allée de Brienne, 31170 Toulouse, Email: olivier.brossard@ sciencespo-toulouse.fr, phone: \\ +33(0)561128721 \\ **Corresponding author: University of Toulouse; Political Studies Institute, Economics department \\ (LEREPS), Manufacture des Tabacs, MD 207, 21 allée de Brienne, 31170 Toulouse, Email: \\ susanna.saroyan@ut-capitole.fr, phone: +33 (0)5 61128709
}

\begin{abstract}
:
We study at an individual level the prices that banks pay for liquidity, measured here by overnight rates charged for unsecured loans on the e-MID trading platform, which is an important and transparent money market for European banks. Using data from both before and within crisis sub-periods, we provide evidence that borrower's and lender's own liquidity status has a significant impact on overnight rates, both before and during the turmoil periods. We first review the literature focused on the role of liquidity risk in the recent interbank turmoil. We then implement an integrative LSDV estimation to assess the determinants of eMID overnight rates. In these regressions, we put together measures of the three types of factors that have received theoretical and empirical support, namely, counterparty risk, liquidity factors and market imperfections. We find that even when counterparty risk and market imperfections are controlled for, banks with higher funding liquidity risk pay an interest rate premium. We show that this is probably explained by hoarding and shortsqueezing behavior of liquidity-long banks. These phenomena disappeared when the ECB launched its full allotment policy in October 2008.
\end{abstract}

Key Words: Funding liquidity; Liquidity risk; Overnight interest rates; hoarding; shortsqueezing.

JEL: E42, E58, G21, G28 
${ }^{A}$ We thank the Regional Council of Aquitaine region for funding part of this research upon the project "Liquidity, Crisis and Regulation" in collaboration with Bordeaux IV University.

\title{
Hoarding and short-squeezing in times of crisis: evidence from the Euro overnight money market
}

\begin{abstract}
:
We study at an individual level the prices that banks pay for liquidity, measured here by overnight rates charged for unsecured loans on the e-MID trading platform, which is an important and transparent money market for European banks. Using data from both before and within crisis sub-periods, we provide evidence that borrower's and lender's own liquidity status has a significant impact on overnight rates, both before and during the turmoil periods. We first review the literature focused on the role of liquidity risk in the recent interbank turmoil. We then implement an integrative LSDV estimation to assess the determinants of eMID overnight rates. In these regressions, we put together measures of the three types of factors that have received theoretical and empirical support, namely, counterparty risk, liquidity factors and market imperfections. We find that even when counterparty risk and market imperfections are controlled for, banks with higher funding liquidity risk pay an interest rate premium. We show that this is probably explained by hoarding and shortsqueezing behavior of liquidity-long banks. These phenomena disappeared when the ECB launched its full allotment policy in October 2008.
\end{abstract}

Key Words: Funding liquidity; Liquidity risk; Overnight interest rates; hoarding; shortsqueezing.

JEL: E42, E58, G21, G28 


\section{Introduction}

The recent financial turmoil has revealed overlooked fragilities in the wholesale money market, when the spreads of short-term interbank loans started to become exceptionally large and volatile during summer 2007. According to the expectations theory of the yield curve, current and expected short-term interest rates influence all other rates. They consequently form the first stage of the monetary policy transmission mechanism. That is why a large theoretical and empirical body of literature has developed around the determinants of these tensions in interbank markets. Several significant advances have been made that show that both solvency and liquidity problems have played a role in the evolution of money market rates during this troubled period. However, the contribution of liquidity risk among these factors remains controversial. Some rigorous empirical studies that tried to disentangle the components of money market spreads over the crisis period obtained disappointing results regarding the impact of liquidity risk and liquidity hoarding behaviors (Angelini et al. 2011, Afonso et al. 2011a, Afonso et al. 2011b). In the same perspective, some event studies of central bank interventions during the turmoil found that the provision of supplementary liquidity did not relieve interbank tensions. Their authors consequently concluded that public liquidity crowds out private liquidity in a context of elevated counterparty risk and high asymmetric information (Taylor and Williams 2009, Brunetti et al. 2011). These empirical results are supported by various modeling endeavors that conclude in favor of the explanation of the interbank market freeze by solvency or adverse selection problems (see, e.g., Flannery and Sorescu 1996, Flannery 1996, Furfine 2001, Freixas and Jorge 2008, Heider et al. 2009).

This set of results challenges the view that lender of last resort interventions would be an efficient resolution mechanism for interbank market crises. They also question the emphasis put by central bankers and prudential regulators on banks' liquidity position and the ongoing implementation of the two liquidity ratios proposed in the Basel 3 framework. If insolvency and asymmetric information are the roots of all evil, lender of last resort interventions are at best relevant to curing market liquidity problems, but they are useless in treating liquidity hoarding in the interbank market. The only relevant treatment for the latter disease would be to restructure insolvent banks and reduce asymmetric information by publishing stress tests or any other type of relevant information on banks' solvency (Brunetti et al. 2011).

Nevertheless, a number of theoretical and empirical papers now suggest that liquidity problems indeed played a role during the interbank market turmoil. On the theoretical side, contagious liquidity shocks are convincingly modelled, for example, in Allen \& Gale (2000), and Allen et al. (2009). Other theoretical models more specifically focused on money markets show that hoarding and overpricing of liquidity can be a rational behavior for lenders (e.g., Eisenschmidt and Tapking, 2009, Acharya and Skeie, 2011) and for borrowers (e.g., Nyborg and Strebulaeev, 2004, Valimaki, 2008). On the empirical side, several papers confirm that interbank markets do not always allocate liquidity efficiently. Some recent studies have shown that banks fearing to be liquidity-short pay interest rate premiums during the Main Refinancing Operations (MRO) of the European Central Bank (ECB), in normal times as well as during turmoils (Bindseil et al., 2009, Eisenschmidt et al., 2009, Drehman and Nikolaou, 2010, Fecht et al. 2011). There is also a series of empirical results showing that both aggregate and individual liquidity positions significantly contribute to interbank rates dynamic during the crisis (e.g., Michaud and Upper 2008, De Socio 2011, Beirne, 2012, Acharya and Merrouche 2013, Soares and Rodriguez 2013). Lastly, several studies show that liquidity provision by central banks actually relieved interbank markets during the crisis (McAndrews et al. 2008, Christensen et al. 2009, Hesse and Frank 2009).

In this paper, we add new results to the empirical literature that studies the liquidity premium paid by banks on money markets. Most previous cross-sectional studies focused on 
the primary money market and therefore examined banks behavior during auctions organized by central banks for their main refinancing operations. They all argue that the significant liquidity premium observed in this primary money market is explained by the two following rationales: banks expecting to be liquidity-short would overbid at the repo auctions because they fear either being squeezed by liquidity-long banks on the secondary money market or because they do not want to experience the stigma effect of borrowing at the marginal lending facility. However, there is still a lack of evidence that banks borrowing in the secondary money market actually have to pay a liquidity premium because they are squeezed by their liquidity-long pairs. We only know of one cross-sectional study on the secondary Sterling money market made by Acharya and Merrouche (2013), which found that individual unsecured overnight spreads vary significantly with the liquidity held by other banks but not with the bank's own liquidity endowment.

We obtain different results for the Eurozone because both the own liquidity position of borrowers and the liquidity situation of lenders appear to influence significantly the individual overnight rates in our estimations. We also differ from the two other studies that exist on the interbank Euro Money market because we work at an individual bank level whereas they use aggregate EONIA spreads (Beirne, 2012, Soares and Rodriguez 2013).

We implement an integrative approach to estimate the determinants of e-MID overnight interbank rates, in which we try to integrate relevant measures of the three types of factors that have received theoretical and empirical support in recent years, namely counterparty risk, liquidity balances and market imperfections. e-MID SIM S.p.A. is a multilateral electronic platform where nearly 200 Italian and European banks exchange unsecured interbank deposits and Overnight Indexed Swaps. It is one of the two multilateral trading devices in the European interbank unsecured deposit market and, according to the ECB Financial Integration Report, e-MID accounted for $17 \%$ of the total turnover of the unsecured segment of the Euro market before the crisis. e-MID is the only publicly available source of micro data on interbank uncollateralized transactions in the Euro area because the majority of short-term interbank transactions are negotiated over the counter. Publicly disseminated EONIA, LIBOR and EURIBOR rates are averaged over a limited panel of large banks in a way that does not allow cross-sectional analysis. Moreover, e-MID rates are those of actual transactions and therefore do not suffer from the potential distortions affecting LIBOR and EURIBOR rates.

A couple of recent papers use e-MID data to analyze overnight interbank rates, but we differ significantly. First, we cover a larger period before and after the onset of the "subprime crisis": our dataset starts on January 2, 2006, and ends on December 31, 2009, whereas most studies on e-MID cover 2006 to mid-2008 ${ }^{1}$. More importantly, to the best of our knowledge, this is the first study to obtain evidence of a funding liquidity effect in a cross-sectional decomposition of the e-Mid overnight rate. Cassola and al. (2010) Kapar and Iori (2011) and Liberati et al. (2012) use similar data but focus on the determinants of market fragmentation and market power. Gabrieli et al. (2012) mainly concentrate on connectedness issues. Brunetti et al. (2011) implement an event study of the impact of ECB's intervention news on e-MID overnight rates but do not account for banks' individual levels of liquidity. Michaud and Upper (2008) employ e-MID rates as indicators of market liquidity but estimate funding liquidity as a residual. More similar to ours is the paper by Angelini et al. (2011) in which they explain the spread between e-MID rates and average Eurepo rates by a complete set of variables accounting for credit risk, balance sheet liquidity factors and various market imperfection measures. However, they study term rates (one week and more) and their

\footnotetext{
${ }^{1}$ In many papers authors provide studies until the passage to the Fixed Rate Full Allotment (FRFA) MRO auctions by the ECB (October 2008). In this paper we extend our study up to the announcement date of new 1year FRFA LTROs by the ECB. We consider that at least until that period the interbank market still provides relevant information about banks' funding needs.
} 
liquidity variables prove non-significant. On the contrary, we find that all three types of factors contribute to the dynamic of e-MID overnight rates over the period, and the impact of our measures of borrowers and lenders' liquidity positions are significant and even more so after the start of the crisis.

In section 2, we review the theoretical and empirical literature related to the role of funding liquidity in the recent interbank turmoil. In section 3, we describe our data and estimation specificities. In section 4, we comment on results from regression specifications that test whether liquidity position matters across different periods before and after the onset of the subprime crisis. Finally, section 5 concludes the paper.

\section{Over-pricing of liquidity in money markets: theoretical foundations and empirical evidence}

The liquidity crisis that hurt money markets during the subprime crisis can be shortly described as a paradoxical situation wherein some lenders preferred to hoard liquidity even if some borrowers were ready to pay a substantial premium for that liquidity. Consequently, raising cash- on short notice became particularly difficult and costly. To understand such an event, it is useful to begin with a reminder of some theoretical definitions of funding liquidity. They are helpful to understanding the liquidity preference behaviors that partly explain the money-market freeze of 2008; they also help in understanding why it is difficult to build relevant liquidity indicators.

Some authors make a clear distinction between funding liquidity on the liability side, which is defined as the ability to borrow in order to settle obligations, and funding liquidity on the asset side, which completely depends on market liquidity because it is defined as the ability to sell assets in order to settle obligations (Tirole 2010). Other authors consider that these two modes of raising cash are the two sides of the same coin (Borio 2000, Strahan 2008, Brunnermeier and Pederson 2009). It is true that securitization operations are supported by contingent lines of credit, which means that the originator uses both asset and liability management to obtain liquidity. However, the conceptual distinction between the liability and the asset side of funding liquidity proves useful because the reasons that make liquidity available or unavailable on each side of the balance sheet are not the same and do not require the same indicators to be detected empirically.

Regarding funding liquidity on the liability side, the key issues are a) why and when do some lenders refuse to offer the quantity of liquidity that they would have offered in normal times and b) why are some borrowers ready to pay an excessive price for this liquidity? In money markets, potential lenders may hoard liquidity because of a precautionary motive due to various reasons: payments uncertainty (Acharya and Merrouche, 2013, Holmström and Tirole, 2011), increasing anticipations of rollover risk (Acharia and Skeie 2010), bad news regarding inadequately understood financial innovations (Caballero and Krishnamurthy 2008, Krishnamurthy 2010) or, lastly, elevated asymmetric information making lenders unable to differentiate illiquid counterparties from insolvent ones (Flannery 1996, Freixas and Jorge 2008). Opportunistic conduct may also drive up the price of liquidity. For instance, during central banks' main refinancing operations, banks with high collateral endowments may borrow more than they need in order to acquire a market power in the secondary money market. Moreover, the way the ECB conducts its MROs, i.e., fixed or variable rate tenders, respectively aggravates or alleviates the short-squeezing problem (Nyborg and Strebulaeev, 2004; Bindseil and Nyborg, 2007). The impact of the first stage liquidity allocation on the interbank rates has been empirically evidenced for the Eurozone (Bindseil et al., 2009, Eisenschmidt et al., 2009, Fecht et al. 2011). Another strategic behavior consists in refusing to 
lend in money markets in order to force needy banks to fire-sell their assets at a discount price (Acharya et al. 2009).

On the asset side, funding liquidity depends on whether the securities held will be easily tradable. In normal times, it depends on market microstructure characteristics such as deepness, resilience and trading costs. In bad times, the main determinant of the liquidity of an asset class is whether some agents will be eager to buy when many others are willing to sell them. Some authors contend that T-bills do possess this property that allow them to deliver cash when it is most needed, others underline that liquidity spirals can make liquidity vanish in every market segment because of fire sales and liquidity commonalities across stock and bond markets (Chordia et al. 2000). Market liquidity can therefore suddenly dry up on very large portions of the financial marketplace. In terms of measurement, it is clear that market microstructure variables such as bid-ask spreads and volume turnovers only capture the level of market liquidity in normal times. In bad times, the liquid assets are those that attract investors during the "flight to quality" movement. The safest T-bills may provide the required liquidity but they are a scarce resource and, in very bad times, gold or reserve currencies like the Swiss Franc may be considered better stores of value. Moreover, the ultimate liquidity is the most universally acceptable debt settlement medium: commercial bank money for non-monetary agents; central bank money for commercial banks. Consequently, the use of stock ratios such as liquid assets over total assets to capture the asset side funding liquidity may prove disappointing when self-fulfilling changes in beliefs modify what the market perceives as liquid assets. If assets become periodically illiquid, stock-based liquidity ratios are not good indicators of individual liquidity positions in bad times.

This suggests that the funding liquidity constraint is better understood if one focuses on the flows of cash that can be generated from both the asset and the liability side of the balance sheet. Focusing on daily bank payments, one can write this constraint according to the following equation:

$$
\Delta B_{t}=\text { outflows }_{t}-\text { inflows }_{t}-\nabla M_{t}^{C B}-\nabla A_{t}
$$

This equation states that the flow $\Delta B_{t}$ of new liquidity that a bank needs to borrow (or lend if $\Delta B_{t}$ is negative) on money markets on day $t$ is equal to the difference of its cash outflows and inflows the same day less any variation in its central bank reserves, $\nabla M_{t}{ }^{C B}$, and less the flow of cash that it can obtain from selling assets on day $t, \nabla A_{t}$. To put it differently, a bank can fill the gap between its outflows and inflows by either depleting its stock of assets (if liquid enough) or cash reserves at the central bank, or by borrowing on money markets ${ }^{2}$.

Funding liquidity risk implies that a bank may be at the same time stock-liquid and flow-illiquid: liquid in the sense that its stocks of assets $A_{t}$ and central bank deposits $M_{t}{ }^{C B}$ are reasonably large, and illiquid in the sense that it suffers from larger than usual outflows on day $t$ and cannot sell enough assets because of market illiquidity nor withdraw enough of its central bank deposits because of legal reserve requirements constraints. Of course, it is possible in such a situation to borrow at the central bank's standing facilities (the lending facility in the Eurozone), but at a penalty rate. Consequently, banks prefer borrowing on the overnight money market to avoid this penalty as well as the stigmatization resulting from emergency discount window borrowing.

The presence of funding liquidity risk, theoretically modeled as a consequence of insurance against possible short-squeezing (Nyborg and Strebulaeev, 2004) or of banks' increasing risk aversion (Valimaki 2006) has been evidenced by a range of empirical studies focusing on the bid rates of the ECB's variable rate MRO auctions. In a study of the behavior of German banks during the weekly MROs of the ECB between June 2000 and December

\footnotetext{
${ }^{2}$ For a slightly different presentation of this constraint, see Drehman and Nikolaou (2013).
} 
2001, Fecht et al. (2011) show that the price individual banks pay for liquidity within MRO auctions are higher when liquidity distribution is more uneven across banks. They also find that small banks with negative excess reserves bid more aggressively as they are the easiest prey to be squeezed because of their limited access to interbank funding. Moreover, according to Fecht et al. (2011) when the liquidity imbalances are large, all banks tend to pay more for liquidity the shorter their reserve positions. This presence of the funding liquidity risk even in normal times is confirmed in our empirical results regarding the secondary money market of the Eurozone (section 4 below). Similarly, Drehmann and Nikolaou (2013) show that the funding liquidity risk premium measured by the gap between bid rates and the expected marginal ${ }^{3}$ rate of the auctions is positive, low and stable in normal times but occasionally goes through large spikes during key moments of the subprime crisis before the implementation of the new fixed rate-full allotment MROs since October 2008.

A few studies also evidence a funding liquidity risk premium in interbank markets. Acharya and Merrouche (2013) study the Sterling interbank market at both aggregate and individual levels. At the aggregate level, they find that the average secured and unsecured interest rate spreads (with policy rate) paid before the crisis by large UK settlement banks are negatively influenced by the aggregate overnight liquidity buffers held by those banks. However, they show that the correlation is inverted during the crisis, which provides evidence of liquidity hoarding: in stressed times, the funding cost is so high because of increasing market illiquidity, stigmatization of marginal borrowing facilities, etc., that banks prefer bearing the opportunity cost of keeping excess reserves and accept release of their liquidity only at a price exceeding the cost of alternative funding sources. These authors also show that individual unsecured overnight spreads paid by UK settlement banks are negatively correlated with the total liquidity held by other banks pre-crisis and positively so during the crisis but remain independent of the own individual liquidity endowment during the entire observation period. Beirne (2012) and Soares and Rodriguez (2013) study the EONIA spread and find that aggregate excess liquidity has a significant negative effect on the spread both before and during the turmoil (liquidity effect). Contrary to Acharya and Merrouche 2013, they do not provide evidence of an inversion of the correlation between excess liquidity and interbank rates during the crisis. This could be because reserve targets are self-determined in the UK monetary policy framework whereas there is a compulsory reserve requirement system in the Eurozone that may render liquidity hoarding unnecessary in times of crisis. However, by using cross-sectional data on the Euro system, we manage to differentiate borrowers' and lenders' liquidity positions and we find that they have effects of opposite signs on the individual rates paid by banks on the unsecured Euro overnight money market. This approach has the great advantage of providing separate estimates of the two main components of funding liquidity risk: the fear of stigma and liquidity squeeze that lead liquidity-short banks to bid more aggressively and propose higher short-term rates on one side; the market-power and precautionary motives that conduct liquidity-long banks to require and obtain higher rates when they have built up a larger stock of excess reserves.

\section{Data, Variables and Regressions}

\subsection{Data}

Our principal data source is the e-MID market, an Italian electronic platform providing exploitable micro-data on effective European unsecured interbank transactions. Established in 1990, e-MID was initially limited to coordinating domestic uncollateralized interbank trades

\footnotetext{
${ }^{3}$ Marginal MRO rate is the lowest, stop-out rate of the auction. Whereas the bids above marginal rate that are fully allotted, bids allotted at the marginal rate are usually pro-rata rationed according to the ECB benchmark liquidity provision. For a complete description of the ECB's refinancing procedures, see e.g. Bindseil (2004) or Valimaki (2008).
} 
made in local currency only. Nevertheless, since the EURO creation, its role has been largely expanded to host other European and foreign participants and to insure transactions in four different currencies: EURO, USD, GBP and PLN (Polish Zloty). We possess data on the EURO-quotes executed via e-MID between January 2, 2006 and December 31, 2009. However, we stop the econometric analysis when the ECB launched its program of 1-year fixed rate full allotment "Longer-Term Refinancing Operation" (LTRO), on May 7, 2009. These operations considerably decreased the activity of the overall European interbank (i-b) market during a rather long period. We define the pre-crisis period as the time span between January 2, 2006 and August 9, 2007. Within the crisis period, we consider three sub periods: the turmoil period before the failure of Lehman Brothers (August 9, 2007, to September 14, 2008); the turmoil period including the failure of Lehman Brothers (August 9, 2007, to October 7, 2008); and the FRFA-MROs period going from October 8, 2008, to May 7, 2009. We differentiate this last sub-period because we expect that all types of liquidity position effects should be wiped out when ECB's MROs switched to a Fixed Rate Full Allotment (FRFA) procedure.

e-MID is a screen-based order-driven market on which participant banks post transparent, bid and ask, market orders when they need, respectively, to sell or to buy uncollateralized liquidity at different maturities (both prices and quantities are posted). Maturities for e-MID interbank loans vary from overnight $(\mathrm{O} / \mathrm{N})$ to 1 year. In this paper, we use exclusively overnight loans that represent $91 \%$ of ask and $82 \%$ of bid side maturities. Banks prefer short-term lending because they lend unsecured on e-MID and because overnight trading is one of the most convenient tools for the end of day reserve averaging during the maintenance period. Bid and ask order executions on e-MID are neither price- nor time-priority based. Once orders have been posted, the aggressor hits the order that suits him the best. Counterparties can always refuse the hit, no matter on which market side they are (bid or ask). Refusals are very common and may occur for different reasons: the borrower has no credit line with the lender; the credit line has already been used entirely (generally, the credit limit is unknown to the borrower and is chosen daily by the lender); or there is no agreement on the details of the order sent. The last reason indicates the particularity of e-MID quotes because they can be re-negotiated. According to our e-MID correspondent, the aggressor may change the interest rate or the quantity of the quote it hits. Finally, very few transactions are concluded at the quoter's initial terms (approximately $10 \%$ of transactions).

In our dataset, buyer initiated contracts account for $80 \%$ of overnight transactions. We choose to pool rates of buy- and sell-sides. Hence, we include a control variable representing the weight of buyer-initiated loans (bid side).

\section{e-MID as a part of the European unsecured money market}

European banks have the opportunity to sign unsecured credits either by direct bilateral agreements (OTC), or by intermediation of voice and electronic brokers. In Europe, organized market trading of interbank unsecured loans is exclusively carried out on the Italian e-MID electronic platform and on the Spanish MID platform, which is much smaller. The ECB and some Ministries of Finance supervise e-MID. At least until the beginning of 2009, volumes traded electronically by e-MID represented approximately $20 \%$ of the overall European unsecured market (see ECB's Euro Money Markets Studies of February 2009 and December 2010).

To illustrate the importance of the e-MID dataset in terms of traded volumes on a European scale, we present e-MID daily overnight turnover as a share of EONIA ${ }^{4}$ trades in

\footnotetext{
${ }^{4}$ Eonia stands for Euro OverNight Index Average, which is the effective overnight reference rate for the euro. It is computed as a volume-weighted average of all overnight unsecured lending transactions undertaken in the
} 
Figure 1. As one can observe, in the period going up to the beginning of August 2007 that we define as the pre-crisis sub-period, e-MID overnight trades accounted on average for $53 \%$ of EONIA volumes. Within the pre-crisis phase we often find dates with e-MID volumes almost as important as EONIA ones (sometimes even exceeding). Starting from August 2007, the eMID average share unsurprisingly dropped to $35 \%$ of EONIA turnover. e-MID experienced other activity drops after Lehman Brothers' collapse. A decrease can be observed after the ECB switches from variable rate to fixed rate full allotment auctions for its MROs (October 15, 2008), and another one can be observed after the implementation of the first 1-year FRFA LTRO on June 25, $2009^{5}$ (announced on May 7, 2009).

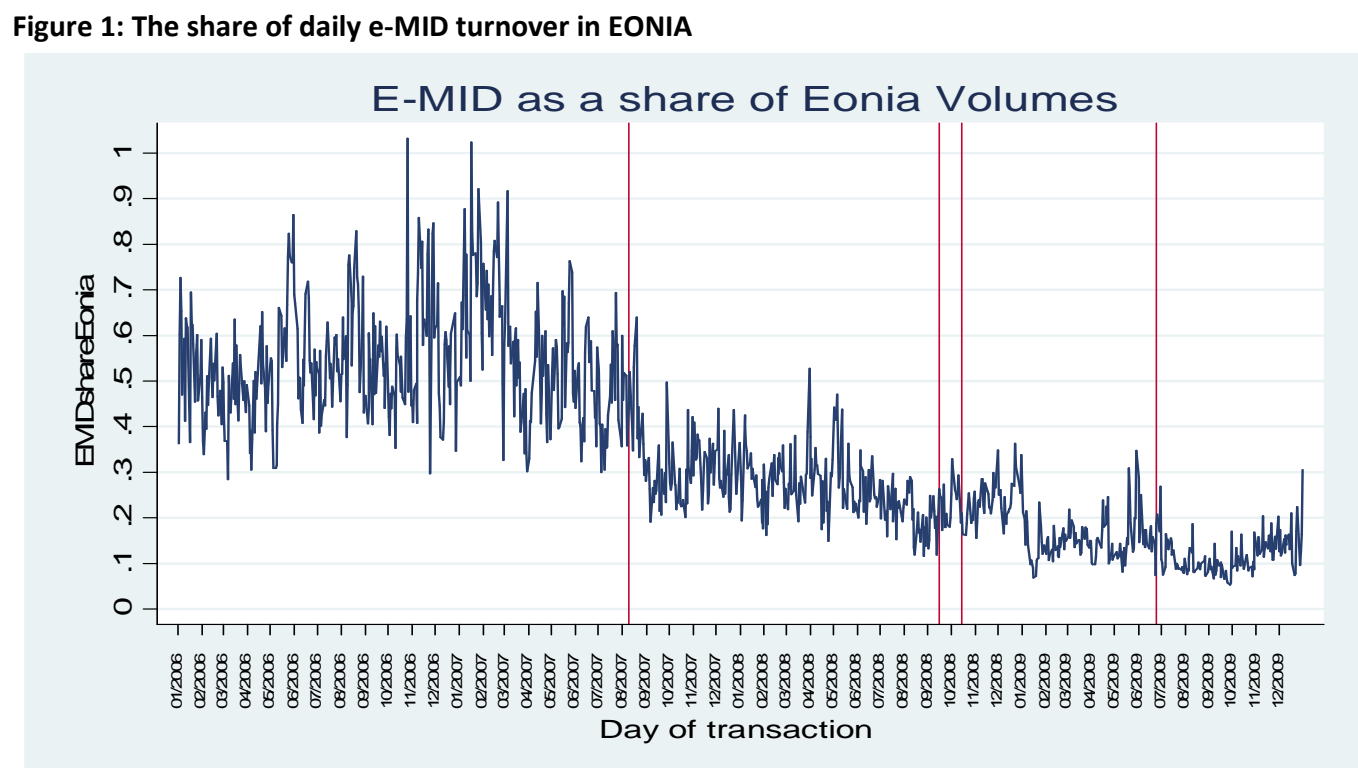

Sources: Authors' computations from e-MID dataset, the ECB's official website.

Representation: e-MID daily overnight turnover as a share of EONIA trades. The first vertical line represents financial crisis breakpoint (August 9, 2007). The second one corresponds to Lehman's failure (September 15, 2008). The third one indicates the implementation of the first full allotment MRO on October 15, 2008. The fourth one represents the first full allotment LTRO at 1 year maturity (June 25, 2009). During that long-term operation 442.42 billion Euros have been allotted to 1121 banks at a fixed rate of $1 \%$

The FRFA-MROs era was also characterized by growing segmentation of the European interbank market (see ECB's survey "Financial Integration in Europe" of April 2010). Some authors (Freixas and Holthausen 2004, Cassola et al. 2010) describe the phenomenon as a result of increasing informational asymmetries between local and foreign financial institutions due to the crisis. Similarly, Figure 2 shows that e-MID's share of international transactions by reserve maintenance period dropped sharply starting from the last months of 2008. Despite the ECB's multiple interventions in the form of unlimited liquidity supply, the European interbank market segmentation continued deepening during 2009 in terms of volumes ${ }^{6}$. In our

interbank market, initiated within the euro area by the contributing banks, known as EONIA Panel. EONIA contributors are the banks with the highest volumes of business in the euro money markets. Today's Eonia Panel consists of 39 banks, but they were about 44 during the period covered by our sample. EONIA rate is calculated by the ECB and published by Reuters every day before 7:00 p.m. Ecuador Time.

5 The ECB announced a program of three 1-year FRFA LTROs on May 7, 2009. During the first 1-year FRFA MRO the ECB allotted about 442.24 billion Euros to 1,121 bidding counterparties at $1 \%$ fixed rate.

${ }^{6}$ According to the ECB's survey "Financial Integration in Europe" of April 2010, the three 1-year unlimited LRTOs of 2009 had quite stabilizing effects on the cross-border dispersion of interbank European rates. However, the situation worsened in terms of volumes traded between European countries. The survey reports decreasing shares of non domestic interbank deposits in 2009 compared to 2008. 
overnight sample, the share of non-domestic trades reached its minimum (below 10\%) during the $3^{\text {rd }}$ quarter of 2009 (after the first 1 year LTRO) ${ }^{7}$. Although the emerging market segmentation was henceforth an evident threat for the European i-b market, e-MID remains representative for the European money market at least during the first two quarters of 2009 because the share of transactions with at least one non-Italian partner still represented approximately $38 \%$ of total overnight turnover ${ }^{8}$. Arciero et al. (2013) consider that the e-MID is representative for the total European i-b market at least until the beginning of the Italian sovereign debt crisis (August 2011).

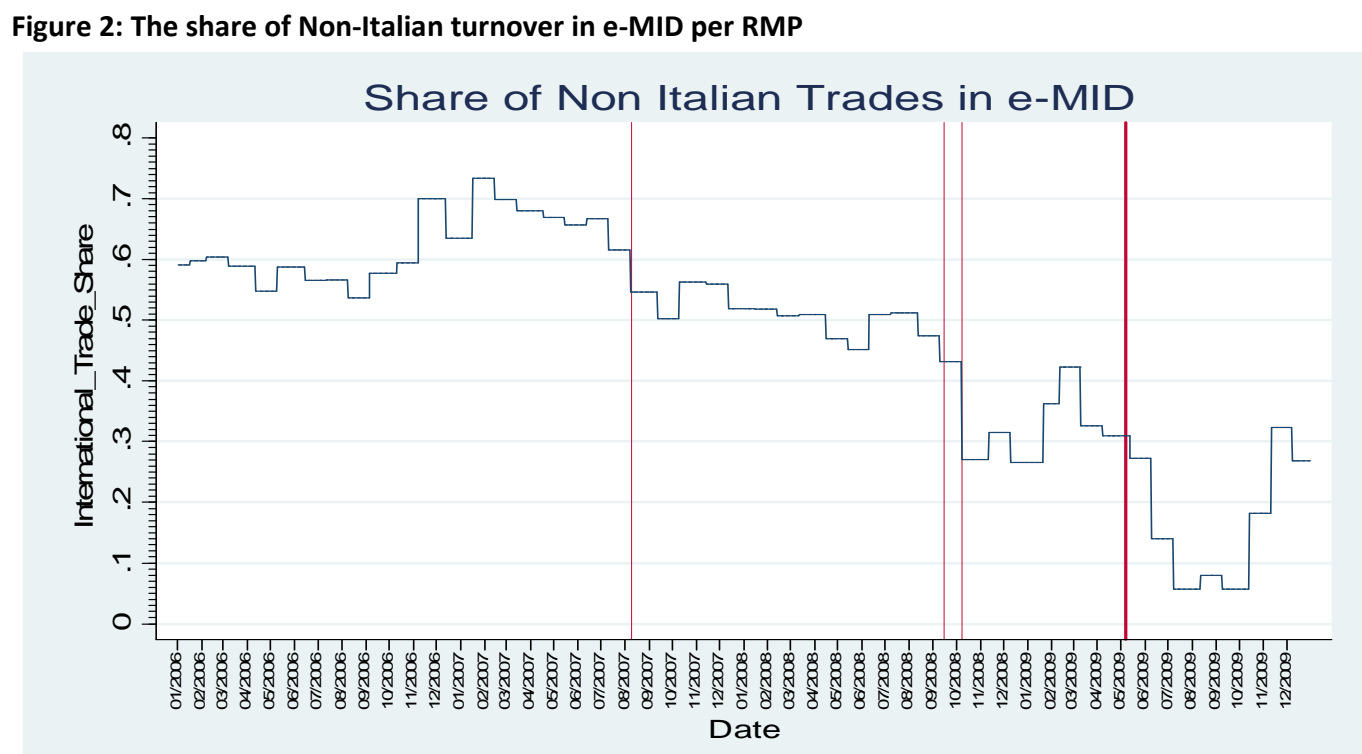

Sources: Authors computations using the e-MID dataset and the ECB's official website

Representation: e-MID's share of non-Italian transactions by reserve maintenance periods. The first vertical line represents the financial crisis breakpoint (August 9, 2007). The second one corresponds to Lehman's failure (September 15, 2008). The third one indicates the announcement date of the full allotment fixed rate MROs allotted on October 15, 2008 (October 8, 2008). The fourth one represents the announcement date of the fixed rate full allotment LTROs of 1-year maturity (May 7, 2009). The first biggest FRFA 1-year LTRO took place on June, 2014 2009. During that long-term operation 442.42 billion Euros have been allotted to 1,121 banks at a fixed rate of $1 \%$.

In Figure 3, we present the dynamics of both the daily volume-weighted average e-MID overnight rate and the EONIA rate among other key rates for the ECB's monetary policy implementation. First, we want to invite readers' attention to the similitude of e-MID and EONIA rates both before and within crisis periods. This fact implies that within the whole period under study the composition of banks trading on e-MID remained quite representative for overall unsecured European interbank market (if we suppose that EONIA survey participants represent Europe). Moreover, Arciero (2010) finds that both before and during the turmoil periods the e-MID rates are quite identical to the OTC rates the author has extracted from the payment system data via Furfine's (1999) algorithm. Second, in Figure 3 one can observe how e-MID (and EONIA) rates react to the changes in ECB's target rates

7 This period coincides with the beginning of the sovereign crisis in Europe. Important co-moments in European state- and bank- debt quality indexes are observed. See, CGFS Paper No 43 "The impact of sovereign credit risk on bank funding conditions" BIS July 2011 for details.

${ }^{8}$ Intragroup activity is not detectable in our dataset. We asked our e-MID correspondent whether intra-group activity was important on e-MID. He answered that this activity was very strong in the past (before the period we study), due to the high fragmentation of the Italian banking industry. However, he also told us that this is no longer a real concern for the period we study (2006-2009) as the consolidation of the industry and the emphasis on operational efficiency (which has led to the concentration of treasury activities) have made the intra-group trading nearly absent nowadays on e-MID. We could not verify whether this affirmation is true or not however. 
(min bid rate if variable rate auctions, and fixed policy rate otherwise), standing facility corridor and to the non-conventional measures the ECB has made use of when concerned by financial stability and monetary policy questions during the crisis. The position of unsecured overnight rates in the standing facility corridor and with respect to the ECB's target rate (EONIA spread) reflects, respectively, the demand for interbank overnight funds (the tightness of overall liquidity conditions) and the ability of the ECB to steer o/n rates to its target. Starting from the FRFA MRO framework the e-MID (and EONIA) rates dropped below the policy rate and became closer to the corridor floor suggesting that European banks over-satisfied their liquidity needs via unlimited MRO auctions and the interbank market was therefore a closer substitute of not holding excess reserves rather than of using the borrowing facility of the ECB. This phenomenon became even more persistent after the 1-year FRFA MROs in June 2009, where the aggregate excess reserves have reached to unprecedentedly high levels.

Figure 3: EONIA, e-MID and other key-rates of the ECB's monetary policy implementation

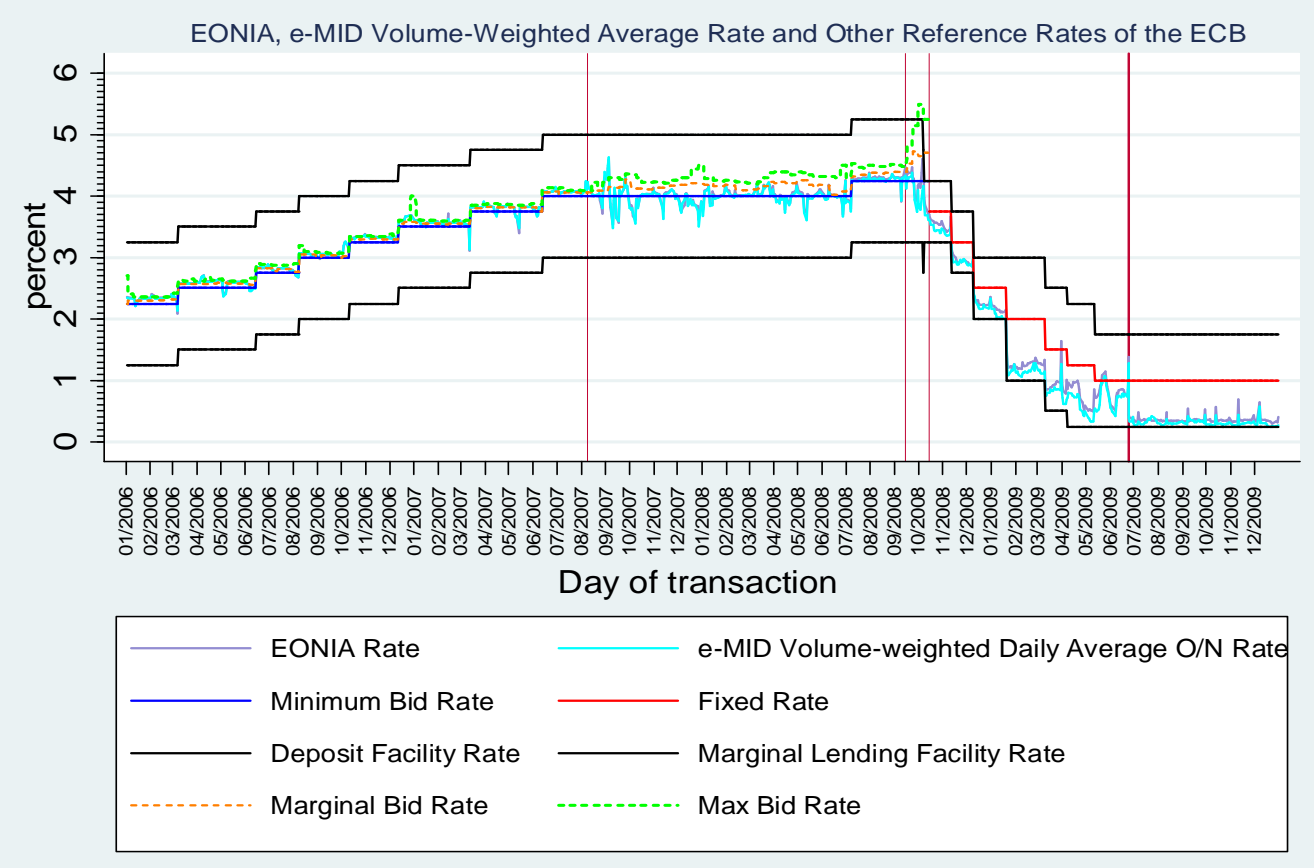

Sources: E-MID dataset and ECB's official website

The first vertical red line represents the financial crisis breakpoint (August 9, 2007). The second one corresponds to Lehman's failure (September 15, 2008). The third one indicates date of the first full allotment fixed rate MROs on October 15, 2008 and the enlargement the list of eligible collaterals for the MRO auctions of the ECB. The fourth one represents the allotment date of the first fixed rate full allotment LTRO of 1 year maturity on June 25, 2009 (announced on May 7, 2009).

\subsection{Variables}

\subsubsection{The dependent variable}

In this paper, we analyze the cross-sectional heterogeneity of European overnight interbank rates using e-MID data. We aim to explain how far different symptoms of market imperfection, such as individual liquidity endowments, bank size, liquidity networks, and market segmentation influence $i-b$ overnight prices before and within financial crisis. We define our dependent variable wate $_{i j, t(n)}$ as the volume-weighted average rate paid by the borrower $i$ to the lender $j$ on day $t$ of the MRO week $n$. This average overnight rate includes 
rates from both lender-initiated and borrower-initiated transactions: if there is any heterogeneity between bid and ask prices, this will be accounted for by a control variable described below.

The total number of banks transacting at least once on e-MID between January 2, 2006 and December 31, 2009 is 201. We differentiate borrowers' and lenders' panels. A bank is present in the former panel if it has been borrower on e-MID at least once over 2006-2009. We define similarly lenders' panel. Among our 201 banks, 178 are present in both lenders' and borrowers' panels, 18 are lenders only, and 5 are borrowers only. There is a large overlapping between these two panels but this is due to the fact that a bank can be present in the borrowers sample even if it borrowed only one time. The same is true for lenders. We demonstrate below that globally, on e-MID net lenders tend to stay lenders and net borrowers tend to stay borrowers.

\subsubsection{Independent variables}

\section{The Net Interbank Liquidity Position}

As already explained above, the overnight interbank market is banks' preferred funding source to adjust their end-of-day reserve holdings. In the Eurozone, the legal requirement is to maintain a bank's balance sheet based amount of average reserves over a period called the Reserve Maintenance Period (RMP). Following the chronology defined in the reserve management literature (see, e.g., Poole (1968)), we suppose that banks first try to obtain the needed liquidity on the weekly MRO auctions and then borrow (lend) deficit (surplus) on interbank markets after the within-day individual liquidity shocks occurred. In the Eurozone, a bank has the possibility to manage its reserve holdings between two MRO auctions either via the interbank market or by using the ECB's standing facilities available at penalty rates 9 . Thus, the net interbank borrowing (or lending) level within this specific time span can be a good proxy to measure bank's reserve position and its dependence on the interbank market ${ }^{10}$.

To construct our liquidity position variables, we use the information on RMP periods, MRO allotment dates and MRO settlement dates provided on the ECB's website. A given net interbank liquidity position does not provide the same bargaining power to a bank when the aggregate level of excess (deficit) reserves is high, as when it is low. That is why we chose to use the share of bank's net interbank liquidity position, rather than the pure i-b liquidity to explain interest rates. We compute the net interbank borrowing amount (lending, if negative) of each bank for every MRO week. The $n^{\text {th }}$ MRO week is the period starting at the settlement date of the $n^{\text {th }}$ MRO auction and ending at the allotment date of the $(n+1)^{\text {th }}$ MRO auction $^{11}$. For the sample we study, we have $176 \mathrm{MRO}$ weeks. We define the variable $N I L P_{i, n}$ as the ratio of the net interbank borrowing (lending if $<0$ ) of borrowing bank $i$ during the MRO week $n$ over the total volume borrowed (lent) within this week.

$$
\operatorname{NILP}_{i, n}=\left(\text { Borrowings }_{i, n}-\text { Lending }_{i, n}\right) / \text { Borrowings }_{n}
$$

\footnotetext{
${ }^{9}$ Note that a bank borrowing at the marginal lending facility is also subjected to the opportunity cost of the collateral and the additional stress-time cost of being stigmatized by its pairs.

${ }^{10}$ As mentioned and demonstrated by Brauning and Fecht 2012, the probability that banks borrow or lend i-b is mainly driven by their reserve holdings within the RMP. These authors show that banks having negative deviations from the required reserves have high probably to be borrowers on the i-b market, and those with positive excess reserves have higher probability to be lenders.

${ }^{11}$ A MRO week never overlaps two different Reserve Maintenance Periods, since every RMP starts on its first MRO auction's settlement date (on Wednesdays) and ends on the first MRO auction's allotment date of the next RMP (on Tuesdays).
} 
We also compute $N I L P_{j, n}$ for each lender $j$ because we want to assess whether lenders with excess liquidity charge a liquidity premium because they hoard liquidity for precautionary reasons or make use of their market power. We regress bilateral overnight rates of trading days $t(n)$ belonging to MRO weeks $n$ (wRate $e_{i j, t(n)}$ ) on the banks liquidity positions of the lagged MRO week (NILP $P_{j, n-1}$ and NILPi,n-l).

It may well be the case that banks borrow and lend similar amounts within MRO weeks because their liquidity shocks show no persistence. In that case, it would be difficult to argue that our NILP variables measure a funding liquidity risk because banks would simply use eMID to reshuffle their non-persistent liquidity imbalances. To check this, we first compute the ratios $\left(\right.$ borr $_{\mathrm{i}, \mathrm{n}}-$ lend $\left._{\mathrm{i}, \mathrm{n}}\right) /$ borr $_{\mathrm{i}, \mathrm{n}}$ if borr $_{\mathrm{i}, \mathrm{n}}>$ lend $_{\mathrm{i}, \mathrm{n}}$ and $\left(\right.$ borr $_{\mathrm{i}, \mathrm{n}}-$ lend $\left._{\mathrm{i}, \mathrm{n}}\right) /$ lend $_{\mathrm{i}, \mathrm{n}}$ if borr $_{\mathrm{i}, \mathrm{n}}<\operatorname{lend}_{\mathrm{i}, \mathrm{n}}$, both for lenders and borrowers. We call them LIQURATIO $_{i, n}$ and LIQURATIO $_{j, n}$. The distribution of these ratios across all banks and MRO weeks is displayed in Figures 4 and 5 below. The ratios converge to zero when individual borrowers (lenders) borrowed and lent almost the same amounts in a given week and they are near one or minus one when the amount borrowed (lent) is much higher than the amount lent (borrowed).

\section{Figure 4: Weekly $L I Q U R A T I O_{j, n}$ computed for lenders}

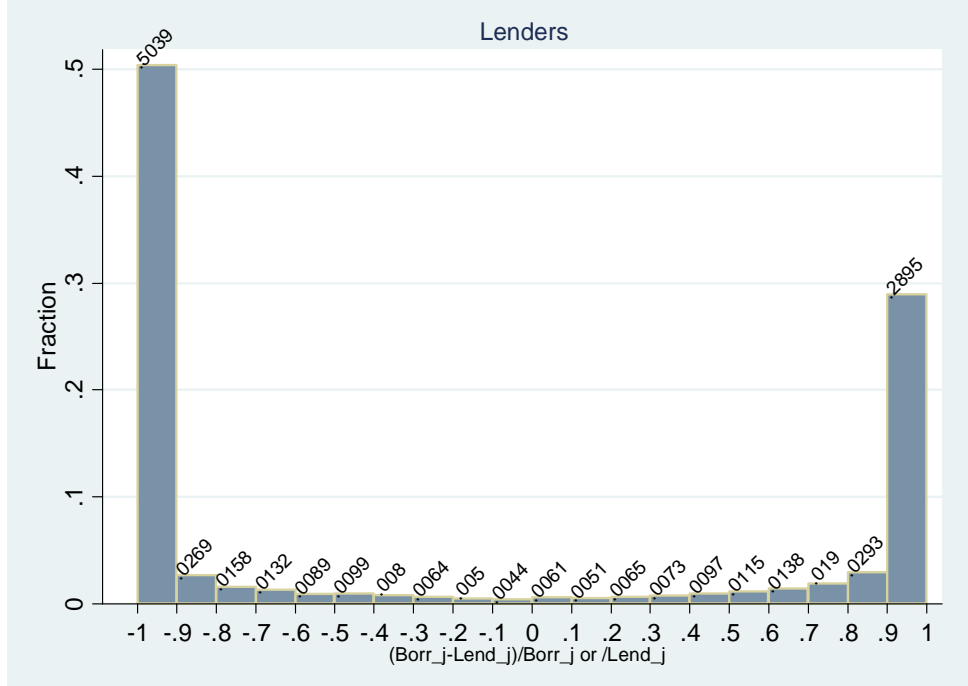

Figure 5: weekly LIQURATIO ${ }_{i, n}$ computed for borrowers

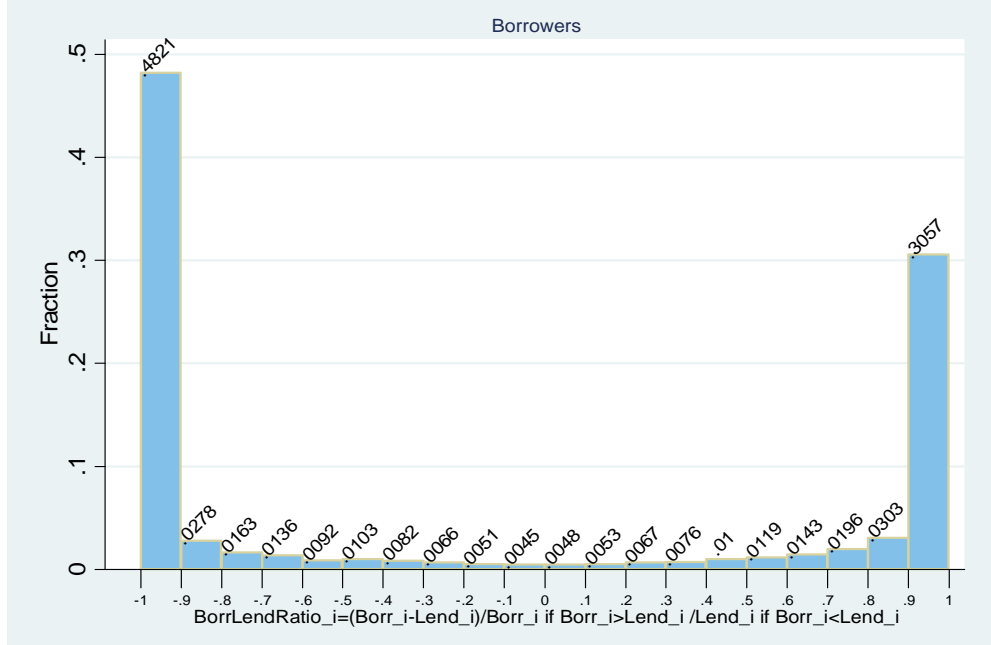


On e-MID clearly, banks do not borrow or lend in a balanced way within weeks. On the contrary, they tend to have well established liquidity statuses within each MRO week. This suggests that they really use this market for liquidity funding rather than reshuffling of nonpersistent liquidity imbalances.

However, it may well be the case that banks are not consistently net borrowers or net lenders across MRO weeks because their liquidity shocks show no persistence across weeks. In that case, they would be net borrowers in one week and net lenders the next week. To check this, we compute the fraction of banks that switch liquidity status from one week to another and display the resulting transition matrixes in Tables 1 and 2 below.

\section{Table 1: Borrower's liquidity status transition matrix}

\begin{tabular}{r|rr|r} 
NetBuyer & \multicolumn{4}{|c}{ NetBuyer_Previous } & \\
& 0 & 1 & Total \\
\hline 0 & 13,436 & 1,901 & 15,337 \\
& 87.61 & 17.38 & 58.37 \\
\hline 1 & 1,901 & 9,037 & 10,938 \\
& 12.39 & 82.62 & 41.63 \\
\hline \multirow{2}{*}{ Total } & 15,337 & 10,938 & 26,275 \\
& 100.00 & 100.00 & 100.00
\end{tabular}

For banks belonging to the borrowers' panel, the probability to stay net borrower in week $n$ when they were net borrowers in week $n-1$ or $n-2$ is $82,62 \%$.

\section{Table 2: Lenders' liquidity transition matrix}

\begin{tabular}{r|rr|r}
\multirow{2}{*}{ NetSeller } & \multicolumn{3}{|c|}{ NetSeller_Previous } \\
& 0 & 1 & Total \\
\hline 0 & 8,911 & 1,904 & 10,815 \\
& 82.37 & 11.69 & 39.90 \\
\hline \multirow{2}{*}{1} & 1,907 & 14,386 & 16,293 \\
& 17.63 & 88.31 & 60.10 \\
\hline \multirow{2}{*}{ Total } & 10,818 & 16,290 & 27,108 \\
& 100.00 & 100.00 & 100.00
\end{tabular}

For banks belonging to the lenders' panel, the probability to stay net lender in week $n$ when they were net lenders in week $n-1$ or $n-2$ is $88,31 \%$.

We thus conclude from figures $4 \& 5$ and tables $1 \& 2$ that, on e-MID, liquidity status (or net interbank positions) are persistent both within and across weeks.

If there are some dealer banks on e-MID, they should trade frequently on the two sides of the market and, possibly, they should also tend to borrow and lend similar amounts on average. Note that Figures 4 and 5 already show that, on weekly basis, there are very few banks/weeks that display a near zero LIQURATIO (around 1\% of observations in borrowers and lenders samples). However, dealer banks may balance their trades on the two sides of the market across weeks rather than within weeks. To check this, we average the LIQURATIOs computed above for each bank over the entire period (2006-2009). The distribution of the 
average absolute values of those ratios for all participating banks is displayed in Figure 6 below.

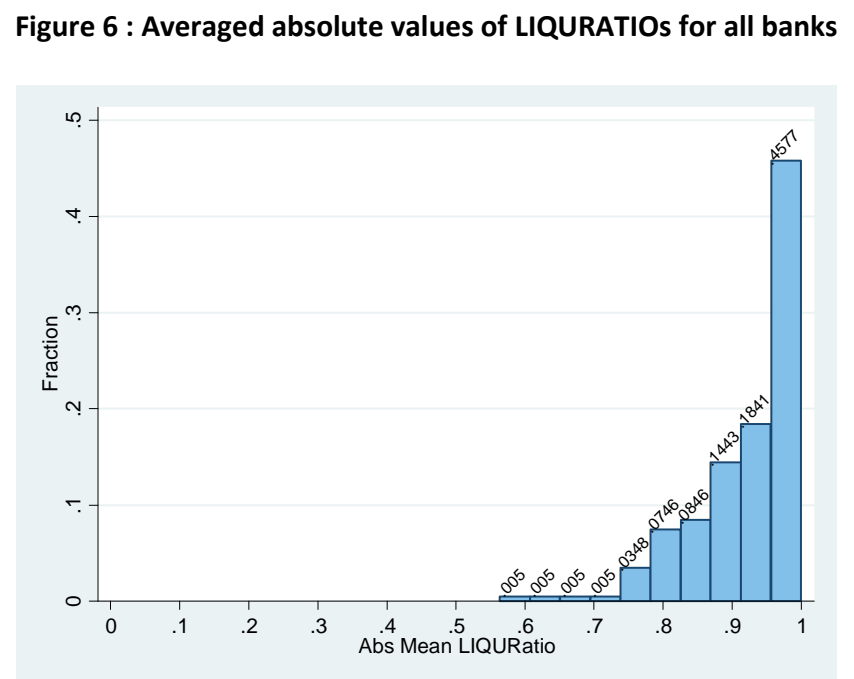

Very few banks have the average ratio near zero. It is thus impossible to define dealer banks as those trading similar volumes on the two sides of the market. As a consequence, to identify dealer banks, we first compute the number of days each bank acted as both lender and borrower. We then divide this figure by the number of days the bank has been active on eMID. We consider that the borrower or the lender bank is a "dealer" if it traded on the two sides of the market the same day in more than $30 \%$ of its overall trading days, and we create the dummies dealerborr and dealerlend accordingly. According to this definition, we identify 16 "dealers" which are all Italian banks except one Greek bank ${ }^{12}$. The 30\% threshold represents the $90^{\text {th }}$ percentile of the variable for the panel of participating banks.

\section{Banks' size proxy}

Because bank size is empirically proven to influence banks' funding ability, we construct size variables following Gabrieli (2012) who also uses e-MID data with encoded identities that do not allow identification of participating banks. Based on their overall precrisis turnovers we classify the whole sample of lenders and borrowers in four size groups: Major, Large, Medium and Small banks. Major borrowers or lenders are defined by a precrisis turnover exceeding the $90^{\text {th }}$ percentile of the distribution. Large banks are those having a turnover level between the $75^{\text {th }}$ and the $90^{\text {th }}$ percentiles. We consider that Medium sized banks are those having their turnover level around the median, between the $25^{\text {th }}$ and the $75^{\text {th }}$ percentiles. Finally, banks classified as Small have a pre-crisis trading volume below the $25^{\text {th }}$ percentile. We generate, accordingly, four categorical size dummies both for the overall panel of banks: Major ${ }_{\text {borr(lend) }}$, Large borr(lend) $_{\text {, Medium }}$ borr(lend) and Small borr(lend) $_{\text {. }}$

Table A below presents the number of borrowers and lenders per size group and per market segment (domestic (Italians) vs foreign). In line with other studies that observe effective bank size on e-MID markets, our table reports that in both lenders' and borrowers' panels approximately $62 \%$ of Major and Large banks are non-Italian banks. The share of Italian banks is approximately $70 \%$ among Medium and Small banks. It is not surprising because non-Italian banks trading on e-MID are large international banks that often act as

\footnotetext{
${ }^{12}$ We think that the need of intermediary banks on e-MID might be motivated either by the willingness of lenders to share the credit risk or by settlement reasons. We know that some banks trading on e-MID do not have direct access to the TARGET payment system that is used to settle all interbank European trades.
} 
intermediaries for their own domestic markets. Given that our pre-crisis activity criterion does not allow any size identification for banks entering e-MID after August 9, 2007, we report in parenthesis uniquely the number of banks which have disappeared from the borrower's and lender's panel after that date. We observe that only approximately 4\% (6\%) of Major-Large and $10 \%(7 \%)$ of Medium-Small borrowers (lenders) left the market during the crisis.

Table A: Number of banks by sizes and country

Domestic

Foreign

Total

\section{Borrowers}

$\begin{array}{llll}\text { Major } & 7(0) & 12(0) & 19(0) \\ \text { Large } & 11(2) & 17(0) & 28(2) \\ \text { Medium } & 60(4) & 28(4) & 88(8) \\ \text { Small } & 29(2) & 7(3) & 36(5) \\ \text { Total } & 107(8) & 64(7) & 171(15)\end{array}$

Lenders

$\begin{array}{llll}\text { Major } & 7(1) & 12(0) & 19(1) \\ \text { Large } & 11(2) & 17(0) & 28(2) \\ \text { Medium } & 63(4) & 29(0) & 92(4) \\ \text { Small } & 30(4) & 15(2) & 45(6) \\ \text { Total } & 111(11) & 73(2) & 184(13)\end{array}$

In parenthesis: number of banks of the category that left e-Mid during the crisis. Domestic banks are Italian banks. "Foreign" banks are all the non-Italian ones.

In Figure 7, we display the evolution of average turnovers by size groups. We observe that turnovers of Major and Large banks converge progressively toward the trading volumes of Medium and Small banks starting from August 2007 (20 $0^{\text {th }}$ RMP), but have still remained above the Medium \& Smalls' turnover (borrowing+lending) until the $40^{\text {th }} \mathrm{RMP}$, which corresponds to the announcement period of the FRFA 1-year LTROs. The brutal activity drop of important banks after this date might be related both to the overall i-b activity drop after the ECB's interventions and to the transparence of the e-MID platform. 
Figure 7 : Average RMP turnover per size group in billions

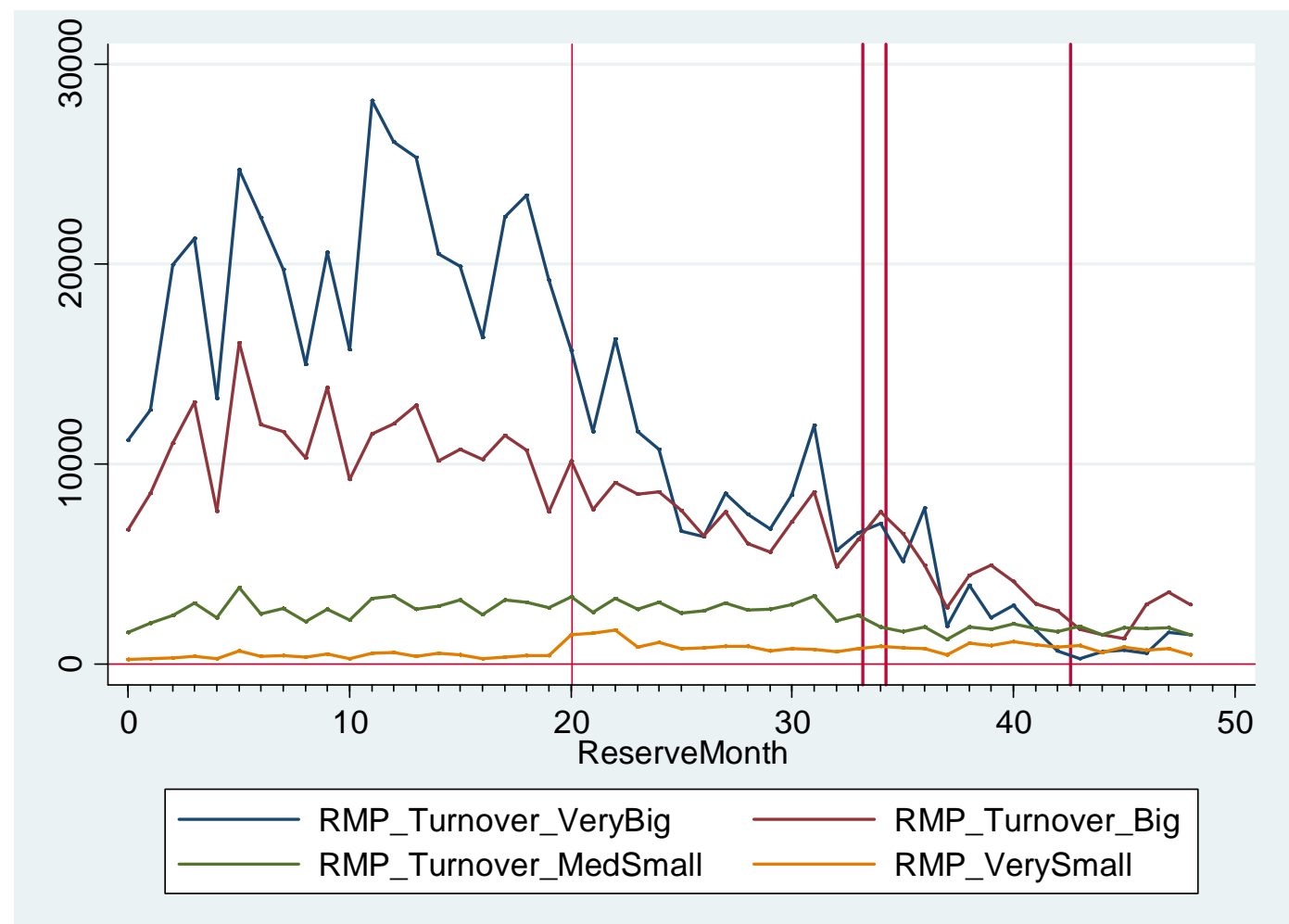

Sources: Authors' computations using the e-MID dataset, the ECB's official website

Representation: Average RMP turnover for each size-group. The first vertical line represents financial crisis breakpoint (August 9, 2007). The second one corresponds to Lehman's failure (September 15, 2008). The third one indicates the implementation of the first full allotment MRO on October 15, 2008. The fourth one represents the first full allotment LTRO at 1-year maturity (June 25, 2009).

\section{Market segmentation and liquidity networks}

Cassola et al. (2010) attribute the important decline in post-crisis i-b trading to the emergence of higher cross-border informational asymmetries. Accordingly, we control for market segmentation frictions by generating two binary variables Inter ${ }_{i, j}$ and Intra $_{i, j}$, identifying inter- and intra-country transactions, respectively. We observe that $87 \%$ of total observations are intra-country, and $93 \%$ of intra-country transactions are intra-Italian. The share of inter-country transactions with at least one Italian partner (borrower or lender) represents $53 \%$ of total cross-border observations.

However, a factor that could mitigate the impact of these increasing informational asymmetries on $\mathrm{i}-\mathrm{b}$ rates is the emergence of so-called liquidity networks. Relationship lending between banks trading on $\mathrm{i}-\mathrm{b}$ markets is the topic of several recent empirical studies (Cocco et al. 2009, Brauning \& Fecht 2013, Affinito 2012). It is expected to become even more vital during the crisis period. We measure the impact of these so-called "liquidity networks" by computing two relationship variables first introduced by Cocco et al. 2009 and commonly used in several other empirical studies on the topic (see. e.g., Brauning \& Fecht 2013, Affinito 2012,Craig \& Fecht2013, etc.): Borrower's and lender's preference indexes, $B P I$ and $L P I$.

They are defined as:

$$
\begin{aligned}
& \text { BPI36 }=\text { Vol }_{i j,(t-36 ; t)} / \text { BorrowVol }_{i,(t-36 ; t)} \\
& \text { LPI36 }=\text { Vol }_{i j,(t-36 ; t)} / \text { LendVol }_{j,(t-36 ; t)}
\end{aligned}
$$


The borrower preference index BPI36 is the fraction of $i$ 's loans borrowed from $j$ during a rolling window of 36 days ${ }^{13}$ over the total interbank e-MID liabilities of borrower $i$ throughout the same period. The lender preference index LPI36 measures the weight of loans from $j$ to $i$ in total interbank e-MID assets of lender $j$ during the 36 days preceding the day $t$.

\section{Controlling for borrower's reputation}

As mentioned in section 3.1, we choose to pool the bid and ask sides of the market. Therefore, to control for possible differences in rates between bid and ask orders, we add to the right hand side of our regressions the variable:

$$
\text { BidWeight }_{i j, t(n)}=\operatorname{BidVol}_{i j, t(n)} / \operatorname{Vol}_{i j, t(n)}
$$

representing the weight of buyer-initiated ${ }^{14}$ loans transacted between lender $j$ and borrower $i$ during the day $t(n)$ of the MRO week $n$. Gabrieli (2012) uses this variable to capture the reputation of the borrower. Others, like Schwarz (2009) who uses e-MID data, argue that banks that prefer hitting a sell order rather than submitting a buy order are those that would hardly find counterparties if they had first shown their identities.

Table B below presents summary statistics of the main variables used in our regressions.

\subsection{Econometric approach and methodological issues}

We aim to understand how the determinants that have been pointed theoretically and empirically as sources of i-b market frictions affect the funding risk of banks before and within the crisis. In particular, we seek to assess whether borrowers that are liquidity 'short' are penalized by their liquidity 'long' pairs who might exert their supply-side market power. It can be a strategic behavior to charge higher rates when one is liquidity-long. According to Acharya and Merrouche (2013), such behavior can also be understood as a form of precautionary liquidity hoarding (see section 2 above).

For that purpose, we regress $w$ Rate $_{i j, t(n)}$, the individual overnight interest rates paid by borrowers $i$ to lenders $j$ on trading days $t(n)$ belonging to the MRO week $n$, on a set of bankand pair-specific variables. We focus especially on the net borrowing position of borrowing and lending banks during the $(n-1)^{t h}$ MRO week $\left(N I L P_{i, n-l}\right.$ and $\left.N I L P_{j, n-1}\right)$, which proxy their reserve situation in the previous MRO week. We drop from our sample all interest rates that are out of the ECB's rate corridor because they represent very particular transactions with borrowers that are probably short of collateral and hence cannot borrow at the ECB's marginal facility (3,262 transactions dropped over an initial sample of 339,005 transactions/rates). We split our sample into before and within crisis periods and run separate regressions for each of them. Because we suspect that sensitivity to funding liquidity risk might become stronger during the crisis and subsequently disappear when the ECB launches its FRFA MROs, we distinguish three sub-periods within the crisis sub-sample: the turmoil period with and without Lehman and the FRFA MROs era, starting on October 8, 2008 and ending on May 7, 2009 (The announcement date for the 1-year FRFA LTROs). We consider that after the first 1-year FRFA allotment the CB funding prevails over interbank funding, and by consequence the individual liquidity positions are no more relevant. All banks have access to unlimited liquidity at the same price. In the Euro system, the thing that could discriminate banks to access liquidity within this period is the stock and the quality of their collateral they need to obtain the ECB funding ${ }^{15}$.

\footnotetext{
1336 days is the maximum number of operational days that a RMP contains in our sample. This ensures capture of the relationships that have been between-banks at least during 1 RMP.

${ }^{14}$ The quoter is the buyer and the aggressor is the seller.

${ }^{15}$ Note that concerned by this problem, the ECB has enlarged the list of eligible collaterals for its MRO auctions
} 
Table B: Definition and summary statistics of main variables

\begin{tabular}{|c|c|c|c|c|c|c|}
\hline Variables & Definition & Obs & Mean & $\begin{array}{l}\text { Std. } \\
\text { Dev. }\end{array}$ & Min & $\operatorname{Max}$ \\
\hline wate $_{i, j, t(n)}$ & $\begin{array}{l}\text { Volume Weighted Average Interest Rates at which } \mathrm{i} \\
\text { borrows from } \mathrm{j} \text { during the date } \mathrm{t} \text { within the } \mathrm{n}^{\text {th }} \text { MRO } \\
\text { week. The variable is expressed in bps }\end{array}$ & 294717 & 305.28 & 119.28 & 25 & 500 \\
\hline BPI36 & $\begin{array}{l}\text { Borrower Preference Index=Borrower i's borrowed } \\
\text { amount from j over i's total borrowings during the } 36 \\
\text { days preceding the date t. The variable is expressed in } \\
\text { percents }\end{array}$ & 293075 & 5.52 & 11.11 & 0 & 100 \\
\hline LPI36 & $\begin{array}{l}\text { Lender Preference Index }=\text { Lender j's lended amount to } \\
\text { i over j's total lendings during the } 36 \text { days preceding the } \\
\text { date t. The variable is expressed in percents }\end{array}$ & 293544 & 8.67 & 13.63 & 0 & 100 \\
\hline$N I L P_{i, n-1}$ & $\begin{array}{l}\text { Net Interbank Liquidity Position } \mathbf{i}, \mathbf{n}-\mathbf{1}=\text { the ratio of the } \\
\text { net interbank borrowing (lending if }<0 \text { ) position of } \\
\text { borrower i during the lagged }(\mathrm{n}-1)^{\mathrm{th}} \mathrm{MRO} \text { week over the } \\
\text { total borrowings (or lendings) within the same period. } \\
\text { The variable is expressed in percents }\end{array}$ & 291493 & 2.17 & 3.41 & -31.3 & 35.57 \\
\hline$N I L P_{j, n-1}$ & $\begin{array}{l}\text { Net Interbank Liquidity Position } \mathbf{i}, \mathbf{n}=\text { the ratio of the } \\
\text { net interbank lending (borrowing if }>0 \text { ) position of } \\
\text { lender } j \text { during the lagged }(n-1)^{\text {th }} \text { MRO week over the } \\
\text { market total lendings (or borrowings) within the same } \\
\text { period. The variable is expressed in percents }\end{array}$ & 290425 & -1.17 & 2.18 & -35.22 & 30.07 \\
\hline BidWeight $_{i, j, t(n)}$ & $\begin{array}{l}\text { Bid Order Weight }=\text { the volume share of buyer initiated } \\
\text { loans transacted between the lender } \mathrm{j} \text { and the borrower } \mathrm{i} \\
\text { during the day t. The variable is expressed in percents }\end{array}$ & 294717 & 75.81 & 42.82 & 0 & 100 \\
\hline Intra $_{i, j}$ & $\begin{array}{l}\text { Intra-National transaction: Dummy }=1 \text { if lender } \mathrm{j} \text { and } \\
\text { borrower } \mathrm{i} \text { have the same nationality and }=0 \text { otherwise }\end{array}$ & 294717 & .87 & .34 & 0 & 1 \\
\hline Inter $_{i, j}$ & 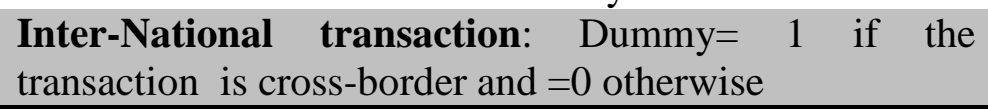 & 294717 & .13 & .34 & 0 & 1 \\
\hline
\end{tabular}


The interest rate paid by $i$ to $j$ on day $t$ contains an average daily component that is driven by the ECB's monetary policy ${ }^{16}$, market expectations and unobserved daily news that may affect interest rates. In this paper, instead of using spreads, we include on the right hand side of every regression daily dummies that will account for daily aggregate liquidity conditions. We thus control for whatever event could affect average daily rates such as calendar effects or ECB interventions. However, because our bank identities are encoded, we have no possibility to observe bank specific variables such as capital ratios, ratings, liquid asset ratios, collaterals or any other determinant of borrower's creditworthiness. Consequently, we include in all regressions a borrower specific dummy to capture its credit quality. One has to underline that even if we are observing unsecured loans, we study the overnight part of the interbank, which implies that the impact of solvency indicators is certainly less important than in cases of long term unsecured loans (Angelini et al. (2011)).

In panel form data, the possible presence of within, between or both correlations of standard errors should be considered. As shown by Petersen (2009), capturing the permanent firm effects by adding firm dummies will not be sufficient to obtain unbiased White standard errors in the presence of temporary firm effects. Temporary firm effects imply that withinfirm correlation of errors changes (dies) over time. The data analyzed in this paper contain long and troubled time periods, which is a good reason to suspect the presence of temporary firm effects. We ran several regressions and compared heteroskedasticity-robust standarderrors (without clustering) with standard-errors clustered separately at borrower and lender levels. We finally choose to report results with standard errors adjusted for clustering at borrower level, as they appeared to be more conservative (higher) than White SEs and the ones adjusted for lender level clustering. Following Cameron et al. (2006) and Petersen (2009), we also tested standard errors adjusted for two-way clustering at borrowertime and lender-time levels, but they did not provide different results and thus we decided not to display them in the paper. Standard errors adjusted for clustering at time level are nearly equal to the heteroskedasticity-robust standard errors (not adjusted for clustering), which means that time effects are permanent and have been correctly controlled for by the day dummies.

Regarding possible endogeneity issues, we can first be reassured by the fact that the data collection process in e-MID is automated in a way that precludes measurement error, and also by the fact that our LSDV estimation method introduces fixed effects in a way that should prevent unobserved heterogeneity from creating endogeneity problems. The more probable sources of endogeneity remaining are therefore selection and simultaneity. Regarding selection, there are two problems. The first one is that some banks leave and others enter e-MID after the onset of the crisis and some banks trade more infrequently than the others and may create artificial interest rate heterogeneity. This could bias our results regarding the liquidity premium if rare or new traders are more sensitive to the funding liquidity risk. In section 4, we provide a two-in-one solution for both outlier and panel unbalancedness problems by running all regressions on a sample of banks that actively participate (lend or borrow) in all the four sub-periods observed. The second selection issue may come from the fact that e-MID is a sub-segment of the European money market that may attract specific banks for which our liquidity and counterparty risk variables are significant whereas this would not necessarily be the case if we had a more representative sample. When interpreting the results, we will have to bear in mind that they are representative of only the banks that trade on e-MID.

\footnotetext{
${ }^{16}$ More precisely, it is driven by the target rate, marginal lending and borrowing facilities, errors in estimating benchmark allotment level, front loading strategies and many other crisis-related modifications in the aggregate liquidity supply procedures.
} 
Finally, one could also suspect a reverse causation between our main independent variables (NILPi,n-1 and NILP $P_{j, n-1}$, the net interbank liquidity positions of borrower $i$ and lender $j$ in week $n-1$ ) and the dependent variable wate $_{i, j, t(n)}$ (the average interest rate paid by borrower $i$ on day $t$ of week $n$ ): if future individual rates were correctly predicted, banks could borrow more liquidity in week $n-1$ because they anticipate higher rates in week n, and this could produce the positive correlation between NILP and wRate $i_{i, j, t(n)}$. However, in that case, banks would be net borrowers in the week before the anticipated rate increase and they would become net lenders during the week wherein they are higher. We showed in section 3.2.2 above that banks trading on e-MID during our observation period do not switch systematically from net borrowers to net lenders in this way. As a consequence, reverse causation does not drive the results.

\section{Results : evidence of a funding-liquidity risk premium}

Table 3 below displays the results of the first specification wherein we assess the impact of borrowers' and lenders' liquidity positions on e-MID overnight interest rates, controlling for day and borrower fixed effects, relationship lending, market fragmentation and bid/ask transaction shares. The sign and statistical significance of the NILPi,n-1 variable confirms our expectation that large net borrowers are penalized when asking for liquidity compared to those that are less money market-dependent. This effect is significant before the crisis, becomes stronger after the onset of the crisis and disappears with the beginning of the FRFA policy. We can use the descriptive statistics from Table A2 to quantify its importance. The coefficient of NILPi,n-1 indicates that, if the net borrowing ratio of a bank increases of one standard deviation $(3,41)$ in the MRO week $n-1$, then its borrowing rates of MRO week $n$ will on average grow of $\left(3,41^{*} 0,059=\right) 0,20$ bps before crisis, of 1,14 bps $(=3,41 * 0,333)$ within crisis pre-Lehman and of 1.19 bps $(=3,41 * 0,349)$ post-Lehman. The effect is small, but comparable to the magnitudes of other coefficients capturing the cross-sectional differences in $\mathrm{O} / \mathrm{N}$ interest rates. This confirms the existence of an individual funding liquidity risk: a bank that has experienced a reduction of its liquidity position in the previous MRO week will pay a liquidity premium in the subsequent MRO weeks either because it has been effectively squeezed by liquidity-long banks (Nyborg and Strebulaeev, 2004) or because it has feared the stigma of borrowing at the marginal facility (Borio and Nelson, 2008, Drehmann and Nikolaou, 2013).

Interestingly, the other side of funding liquidity risk, hoarding by liquidity-long banks, is also evidenced by these regressions. Indeed, the negative and significant coefficient of $N I L P j, n-1$ means that lender $j$ with excess liquidity to lend in the MRO week $n-1$ will charge on average higher rates when lending the next MRO week. Liquidity-long banks seem to squeeze liquidity-short ones and force them to pay a premium related to their market power. This "squeezing" premium is small before the crisis but becomes more substantial in the sequel. The augmentation of the premium imposed by liquidity-long lenders during the crisis suggests that short-squeezing was not the only rationale for hoarding: a precautionary motive due to the rise of liquidity uncertainty might also be at play. 
Table3: Basic Specification

\begin{tabular}{|c|c|c|c|c|}
\hline VARIABLES & ${ }^{(1)}$ Pre-Crisis & ${ }^{(2)}$ TurmoilPreLehman & ${ }^{(3)}$ TurmoilWithLehman & ${ }^{(4)}$ FRFA MRO \\
\hline \multirow[t]{2}{*}{ BPI36 } & 0.003 & 0.007 & 0.010 & -0.031 \\
\hline & $(0.002)$ & $(0.008)$ & $(0.009)$ & $(0.033)$ \\
\hline \multirow[t]{2}{*}{ LPI36 } & $0.009 * *$ & $0.021 * * *$ & $0.027 * * *$ & $0.054 * * *$ \\
\hline & $(0.004)$ & $(0.005)$ & $(0.007)$ & $(0.011)$ \\
\hline \multirow[t]{2}{*}{$N I L P i, n-1$} & $0.059 * * *$ & $0.333 * * *$ & $0.349 * * *$ & 0.099 \\
\hline & $(0.020)$ & $(0.091)$ & $(0.101)$ & $(0.097)$ \\
\hline \multirow[t]{2}{*}{$N I L P_{j, n-1}$} & $-0.018 * *$ & $-0.096 * * *$ & $-0.082 * * *$ & -0.081 \\
\hline & $(0.007)$ & $(0.022)$ & $(0.024)$ & $(0.103)$ \\
\hline \multirow[t]{2}{*}{ BidWeight $_{i, j, t(n)}$} & $-0.010 * * *$ & $-0.027 * * *$ & $-0.031 * * *$ & $-0.059 * * *$ \\
\hline & $(0.001)$ & $(0.002)$ & $(0.002)$ & $(0.006)$ \\
\hline \multirow[t]{2}{*}{ Intrai,j } & $-0.295 * * *$ & $-0.441 * *$ & $-0.527 * * *$ & -0.786 \\
\hline & $(0.087)$ & $(0.201)$ & $(0.192)$ & (1.199) \\
\hline \multirow[t]{2}{*}{ Constant } & $235.231 * * *$ & $426.880 * * *$ & $427.370 * * *$ & $407.084 * * *$ \\
\hline & $(0.174)$ & $(2.209)$ & $(2.202)$ & $(6.447)$ \\
\hline $\mathrm{N}$ of Clusters (Borrowers) & 154 & 146 & 147 & 109 \\
\hline Borrower/Day/Lender FEs & Yes/Yes/No & Yes/Yes/No & Yes/Yes/No & Yes/Yes/No \\
\hline Observations & 140,418 & 85,671 & 90,808 & 28,168 \\
\hline R-squared & 0.994 & 0.828 & 0.806 & 0.993 \\
\hline
\end{tabular}

(1) Regression using pre-crisis subsample: 02.01.2006 to 08.08.2007.

(2) Regression using turmoil subsample before Lehman's collapse (not included): 09.08.2007 to 14.09.2008.

(3) Regression using turmoil subsample included Lehman's default, until the FRFA MRO announcement (not included): 09.08.2007 to 07.10.2008.

(4) Regression using FRFA MRO period subsample: 08.10.2008 (announcement of FRFA MRO) to 07.05.2009 (announcement of FRFA 1 year LTROs).

Coefficients for Borrower and Date fixed effects are not reported.

All standard errors reported in parenthesis are heteroskedasticity robust and clustered at borrower level.

$* * *$ Statistical significance at $1 \%$ level.

** Idem, $5 \%$.

* Idem, $10 \%$. 
One can notice that these results show that the liquidity allocation process is efficient when liquidity positions are non-persistent: if a borrower in week $n$ becomes a lender in $n+1$ he offers a discount; if a lender in $n$ becomes a borrower in $n+1$ he obtains a discount. This is indeed well known from the literature: when liquidity shocks are non-persistent, those that obtain unexpected and unneeded liquidity can reallocate it efficiently to those that suffer an unexpected liquidity drain. However, the signs of our NILP variables also imply that borrowers in week $n$ that stay borrowers in week $n+1$ pay a premium and that lenders remaining lenders charge a premium. This means that the liquidity allocation process is not efficient for those banks that suffer persistent liquidity shocks. Yet we have already shown above in section 3.2.2 that liquidity positions are quite persistent on e-MID for most of the participating banks. A consequence of this is that front-loader banks holding excess liquidity balances long before the end of the Reserve Maintenance Periods use their market power to obtain higher returns in the e-Mid market from those that are back-loaders. This is not efficient because persistently liquidity-long banks should be more eager to lend and thus offer discounts rather than require premiums.

The significance of control variables in Table 3 suggests that funding liquidity risk is not the sole market imperfection creating heterogeneity in individual overnight rates, even if a simple comparison of the coefficients also reveals that, during the crisis, the liquidity positions of borrowers measured by NILPi,n-1 create more heterogeneity than any of the control variables.

First, there is evidence of a market segmentation effect. This problem has been theoretically modeled by Freixas and Holthausen (2004) and empirically evidenced on similar e-MID data by Cassola et al. (2010). They argue that during crises interbank rates tend to be higher for cross-border trades because of increasing informational asymmetries. We confirm that inter-national money market transactions are punished by higher rates compared to domestic ones both before and during the crisis. A cross-border transaction costs on average 0,295 bps more before the crisis and a 0,527 bps more in the crisis period including Lehman's bankruptcy. This premium augmentation confirms the idea of increased informational asymmetries and market segmentation. This premium supported by the European emerging sovereign debt crisis might vary according to counterparty's exact country. Lending to an Irish or to a German bank when you are a French bank should not imply the same risk within this troubled phase. Remember that $53 \%$ of our inter-national transactions include at least one Italian counterparty.

Secondly, we also find evidence of a significant order side effect. We control for possible 'bid-ask' bounce effects by the variable BidWeight described in section 3. We observe that the average rate paid by borrower $i$ to lender $j$ on day $t$ slightly (but significantly) decreases when the share of transactions initiated by the borrower increases. We can relate this result to microstructure effects (Angelini et al. 2009) or to credit quality differences between counterparties who borrow on the buy and sell sides of the market (Schwarz 2009). Schwarz argues that banks preferring to hit a 'sell' order rather than submit a 'buy' order, are those that would hardly find counterparties if they first reveal their identities. At first sight this argument may seem questionable knowing that all hits on e-MID could be easily denied, as the side who posted the proposal discovers the aggressor's identity before accepting the deal. However, what Schwarz (2009) meant in her paper was concerned probably the time of finding a counterparty. This is an overnight market and banks ask for immediate funding. Whereas for a 'good' counterparty, finding quick funding is not a problem, it just has to ask (send a 'buy' order), this may not be true for a 'bad' borrower whose 'buy' order might wait a 
lot before being hit. Thus, 'bad' banks needing quick, overnight refinancing will trade more often on the 'sell order' ('ask') side of the e-MID market. Our results are in line with this reasoning. In all our specifications, we find that lender $j$ will charge lower rates to $i$ if the trade concluded principally on the 'buy order' side of the market. The coefficient of the BidWeight variable is negative and significant at the $1 \%$ level in all specifications, both before and within the crisis. Gabrieli (2012) uses the same variable to capture the reputation of the borrower and find very similar results.

Thirdly, we also control for a possible liquidity network effect. Liquidity networks or customer interbank relationships are supposed to mitigate uncertainties within crisis. The coefficient of the first relationship variables BPI36 (Borrower preference index) is very small, positive, but not significant. Our results concerning this variable are comparable to those found by Brauning and Fecht (2012) who test the impact of borrowing and lending preference indexes on German i-b rates. We cannot evidence that borrowing regularly from the same lender allows negotiating better rates or being more monitored. Concerning LPI36 that indicates to what extend lender $j$ 's i-b assets are concentrated on borrower $i$, we find very similar results to Cocco et al. (2009) and Brauning and Fecht (2012). The coefficient of LPI is positive and significant at the $5 \%$ level before and at $1 \%$ within the crisis: the more a borrower is important and known to the lender the higher is the interest rate charged by the lender. Note that the significance and the amplitude of the LPI36 increase in turmoil times (columns 2 and 3) compared to the pre-crisis period. Moreover, it becomes even more important in times of fixed rate unlimited MROs. These results make us think that the LPI is a measure of concentration of a lender's $i-b$ assets on a single counterparty and must consequently be interpreted as a proxy for undiversified credit risk rather than as a measure of relationship lending. The other interpretation is that lenders prefer diversified credit risks to private information about their counterparties, especially in times of crisis.

\section{Robustness checks.}

\subsection{Varying the liquidity measures}

We first check whether the results regarding the influence of Net Individual Liquidity Positions are due to the choice of one week windows to implement the netting of borrowing and lending positions. For that purpose, we provide in Table A1 in the appendix regressions wherein the variables NILPi,n-1 and NILPj,n-1 have been computed across full RMP periods rather than across MRO weeks. This is a first way to assess whether our results are determined by front-loading and back-loading strategies. Indeed, these strategies may produce unbalanced liquidity positions because, on the one side, front-loaders borrow and do not lend in the first MRO weeks of the RMP, in order to fulfill the average reserve requirement in advance, and then lend and no longer borrow in the last weeks of the RMP. Back-loader banks do the reverse. With NILPs computed over full lagged Reserve Maintenance Periods, the between-banks liquidity imbalances generated by such strategies are smoothed. Table A1

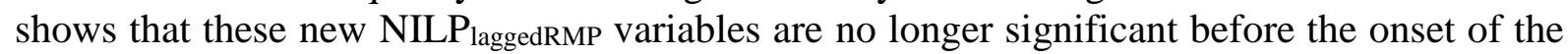
crisis, although they keep the same signs and levels. In the two crisis sub-periods however, the results are not modified: even if we compute Net Interbank Liquidity Positions over full RMP periods, which contain on average four MRO weeks, we still obtain that, during the crisis, net borrowers pay a significant premium when they borrow and net lenders charge a premium when they lend.

We also check robustness of this liquidity risk effect using a volatility-based measure of liquidity risk. We compute the intra RMP standard deviations of daily liquidity shocks (net positions) for both borrowers and lenders. The results, displayed and commented in Appendix 
A2, confirm the interpretation that a funding liquidity risk premium was present on e-MID during our observation period.

\subsection{The individual liquidity position effect for dealer banks}

As discussed in section 3, the pricing conditions of intermediary banks could differ and liquidity risk might not affect them the same way. To check this, Table 4 displays a specification wherein the liquidity position variables are crossed with the dummies Dealerborr and Dealerlend.

Table 4: Specification with liquidity position-dealer bank interaction terms

\begin{tabular}{|c|c|c|c|c|}
\hline VARIABLES & ${ }^{(1)}$ PreCrisis & $\begin{array}{l}{ }^{(2)} \text { Turmoil } \\
\text { PreLehman }\end{array}$ & $\begin{array}{c}{ }^{(3)} \text { Turmoil } \\
\text { WithLehman }\end{array}$ & $\begin{array}{l}{ }^{(4)} \text { FRFA } \\
\text { MRO era }\end{array}$ \\
\hline BPI36 & $\begin{array}{c}0.003 \\
(0.002)\end{array}$ & $\begin{array}{c}0.004 \\
(0.008)\end{array}$ & $\begin{array}{c}0.007 \\
(0.008)\end{array}$ & $\begin{array}{l}-0.032 \\
(0.033)\end{array}$ \\
\hline LPI36 & $\begin{array}{l}0.009 * * \\
(0.004)\end{array}$ & $\begin{array}{c}0.022 * * * \\
(0.005)\end{array}$ & $\begin{array}{c}0.027 * * * \\
(0.006)\end{array}$ & $\begin{array}{c}0.055^{* * * *} \\
(0.011)\end{array}$ \\
\hline NILPi,n-1 & $\begin{array}{c}0.067 * * \\
(0.027)\end{array}$ & $\begin{array}{c}0.215 * * \\
(0.084)\end{array}$ & $\begin{array}{c}0.212 * * \\
(0.091)\end{array}$ & $\begin{array}{c}0.056 \\
(0.119)\end{array}$ \\
\hline NILPi,n-1 $\times$ Dealer $_{\text {borr }}$ & $\begin{array}{l}-0.032 \\
(0.046)\end{array}$ & $\begin{array}{c}0.298 * * \\
(0.139)\end{array}$ & $\begin{array}{c}0.359 * * \\
(0.160)\end{array}$ & $\begin{array}{c}0.099 \\
(0.124)\end{array}$ \\
\hline NILPj,n-1 & $\begin{array}{c}-0.018 * * \\
(0.007)\end{array}$ & $\begin{array}{c}-0.099 * * * \\
(0.023)\end{array}$ & $\begin{array}{c}-0.084 * * * \\
(0.025)\end{array}$ & $\begin{array}{l}-0.040 \\
(0.104)\end{array}$ \\
\hline NILPj,n-1 $\times$ Dealer lend $_{\text {la }}$ & $\begin{array}{c}0.039 * * \\
(0.015)\end{array}$ & $\begin{array}{c}0.199 * * * \\
(0.044)\end{array}$ & $\begin{array}{c}0.203 * * * \\
(0.042)\end{array}$ & $\begin{array}{c}0.279 * * * \\
(0.051)\end{array}$ \\
\hline BidWeighti,j,t(n) & $\begin{array}{c}-0.010 * * * \\
(0.001)\end{array}$ & $\begin{array}{c}-0.027 * * * \\
(0.002)\end{array}$ & $\begin{array}{c}-0.031 * * * \\
(0.002)\end{array}$ & $\begin{array}{c}-0.058 * * * \\
(0.006)\end{array}$ \\
\hline Intrai,j & $\begin{array}{c}-0.303 * * * \\
(0.086)\end{array}$ & $\begin{array}{c}-0.464 * * \\
(0.203)\end{array}$ & $\begin{array}{c}-0.548 * * * \\
(0.192)\end{array}$ & $\begin{array}{l}-0.768 \\
(1.165)\end{array}$ \\
\hline Constant & $\begin{array}{c}235.221 * * * \\
(0.175)\end{array}$ & $\begin{array}{c}427.068 * * * \\
(2.176)\end{array}$ & $\begin{array}{c}427.599 * * * \\
(2.165)\end{array}$ & $\begin{array}{c}407.095 * * * \\
(6.468)\end{array}$ \\
\hline $\begin{array}{l}\text { N of Clusters (Borrowers) } \\
\text { Borrower/Day/Lender FEs } \\
\text { Observations } \\
\text { R-squared }\end{array}$ & $\begin{array}{c}154 \\
\text { Yes/Yes/No } \\
140,418 \\
0.994\end{array}$ & $\begin{array}{c}146 \\
\text { Yes/Yes/No } \\
85,671 \\
0.829\end{array}$ & $\begin{array}{c}147 \\
\text { Yes/Yes/No } \\
90,808 \\
0.807\end{array}$ & $\begin{array}{c}109 \\
\text { Yes/Yes/No } \\
28,168 \\
0.993\end{array}$ \\
\hline \multicolumn{5}{|c|}{$p$-values } \\
\hline $\mathrm{H} 0: N I L P i, n-1+N I L P i, n-1 \times$ Dealer $_{\text {borr }}=0^{(\mathrm{a})}$ & 0.300 & $8.52 e-06$ & $3.30 e-05$ & 0.0148 \\
\hline H0: NILPj, $n-1+N I L P j, n-1 \times$ Dealer $_{\text {lend }}=0^{(\mathrm{b})}$ & 0.223 & 0.0491 & 0.0165 & 0.0492 \\
\hline
\end{tabular}

(1) Regression using pre-crisis subsample: 02.01.2006 to 08.08.2007 included.

(2) Regression using turmoil subsample before Lehman: 09.08.2007 to 14.09.2008.

(3) Regression using turmoil subsample included Lehman, until the FRFA MRO announcement: 09.08.2007 to 07.10.2008.

(4) Regression using FRFA MRO period subsample: 08.10.2008 (announcement of FRFA MRO) to 07.05.2009 (announcement of FRFA 1 year LTROs).

Coefficients for Borrower and Date fixed effects are not reported.

All standard errors reported in parenthesis are heteroskedasticity robust and clustered at borrower level.

*** Statistical significance at $1 \%$ level.

** Idem, $5 \%$.

* Idem, $10 \%$.

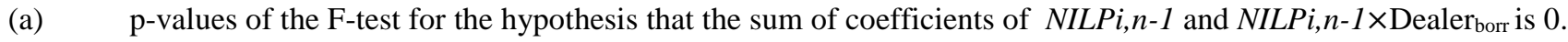

(b) Idem for coefficients of NILPj,n-1 and NILPj, $n-1 \times$ Dealer $_{\text {lend. }}$

First, the significant positive coefficient of the crossed variable $N I L P_{i, n-1} \times$ Dealer $_{\text {borr }}$ in the crisis sub-periods indicates that dealer borrowers paid a liquidity premium that was twice the one paid by non-dealer banks (columns 2 and 3 in Table 4). Lending to an 
intermediary bank means lending indirectly to a range of unknown counterparties. This may explain why dealer banks could be considered riskier in periods of high uncertainty.

Regarding the lender's liquidity position variable, we find that the hoarding behavior evidenced in the previous specification displayed in Table 3 characterizes only the non-dealer lenders. Non-dealers that are liquidity-long charge a rate premium but we see in Table 4 that $N I L P_{j, n-1} \times$ Dealer $_{\text {lend }}$ has a positive and significant sign showing that dealer banks offer a significant discount when they are liquidity-long. This is true before and during the crisis. Only non-dealer banks charged a premium when they were liquidity-long, which we consider the symptom of a hoarding behavior. Dealer-banks probably do not need to hoard liquidity because they have better access to standing facilities.

\subsection{The individual liquidity position effect and the bank size}

In all of the empirical studies cited in this paper, from Furfine (2001) to Brauning and Fecht (2012), bank size appears to be a critical variable for i-b rate formation. The common result is that very large banks enjoy privileged i-b rates compared to small ones. Fecht and al. (2011) show that distributional imbalances and own liquidity shortage affect more heavily small banks than large ones. To assess whether banks of various sizes are more or less affected by own liquidity position variations we run a new specification with crossed variables NILP $\times$ Size $_{\text {borr }(l e n d)}$. Given that we are particularly interested in the relative differences between the small and the larger banks, we chose small banks as the reference category. Note that because we computed the bank size dummies using pre-crisis turnovers (see section 3.2.2.), incorporating these size variables in the regressions forces to omit any new bank entering the e-MID market after August 9, 2007. A few banks are therefore omitted in these regressions (see Table 5). As discussed in Angelini et al. (2009), who observe individual credit qualities of banks, there is no obvious evidence of quality deterioration of the e-MID panel due to this panel variation. Moreover, the small spreads between e-MID, EONIA and OTC market rates observed within the crisis proves that those sample movements do not really marginalize the post-crisis e-MID panel (see Arciero 2010). In any case, we check the impact of sample movements on our results in the robustness test presented below on the so-called "balanced panel".

The results of the specification with size dummies are reported in Table 5. The cost for being liquidity-short differs across bank size. From regression results in column 1, we see that the small banks paid the largest liquidity shortage premium before the crisis. More precisely, they paid 2.4 bps more when their net borrowing shares of the previous MRO week increased by $1 \%$. Considering that our $N I L P_{i, n-1}$ variable reflects the individual reserve position of the borrowing bank, we could say that our pre crisis results validate the arguments of Fecht and al. (2011) concerning higher risks of being 'squeezed' for small banks. However, this interpretation should be done with caution in our case because a $1 \%$ increase in net borrowing share is more important for small than for major, medium and large banks. Net borrowing shares are naturally highly correlated with banks' sizes. Table $\mathrm{C}$ below reports NILP statistics for borrower and lender banks of different sizes. We can see that, for small banks, the interquartile range of the NILP borr variable is $0.34 \%$. For major and large banks, this value is, respectively, $5.13 \%$ and $2.34 \%$. Similar comments can be made regarding lenders' liquidity positions (NILPj,n-1). 
Table 5: Specification with liquidity position-bank size interaction terms

\begin{tabular}{|c|c|c|c|c|}
\hline VARIABLES & (1) PreCrisis & $\begin{array}{l}\text { (2)Turmoil } \\
\text { PreLehman }\end{array}$ & $\begin{array}{c}{ }^{(3)} \text { Turmoil } \\
\text { WithLehman }\end{array}$ & (4)FRFA_MRO \\
\hline BPI36 & $\begin{array}{l}0.004 * \\
(0.002)\end{array}$ & $\begin{array}{c}0.009 \\
(0.008)\end{array}$ & $\begin{array}{c}0.014 \\
(0.009)\end{array}$ & $\begin{array}{l}-0.028 \\
(0.033)\end{array}$ \\
\hline$L P I 36$ & $\begin{array}{l}0.008 * \\
(0.004)\end{array}$ & $\begin{array}{c}0.023 * * * \\
(0.005)\end{array}$ & $\begin{array}{c}0.027 * * * \\
(0.006)\end{array}$ & $\begin{array}{c}0.042 * * * \\
(0.010)\end{array}$ \\
\hline$N I L P i, n-1$ & $\begin{array}{c}2.408 * * * \\
(0.658)\end{array}$ & $\begin{array}{c}0.132 \\
(0.091)\end{array}$ & $\begin{array}{l}-0.204 \\
(0.161)\end{array}$ & $\begin{array}{c}0.361 * * \\
(0.156)\end{array}$ \\
\hline$N I L P i, n-1 \times$ Major $_{\text {borr }}$ & $\begin{array}{c}-2.391 * * * \\
(0.658)\end{array}$ & $\begin{array}{c}0.182 \\
(0.244)\end{array}$ & $\begin{array}{l}0.537 * \\
(0.289)\end{array}$ & $\begin{array}{l}-0.395 \\
(0.267)\end{array}$ \\
\hline$N I L P i, n-1 \times$ Big borr & $\begin{array}{c}-2.287 * * * \\
(0.662)\end{array}$ & $\begin{array}{c}0.250 \\
(0.175)\end{array}$ & $\begin{array}{c}0.600 * * * \\
(0.196)\end{array}$ & $\begin{array}{l}-0.065 \\
(0.226)\end{array}$ \\
\hline$N I L P i, n-1 \times$ Mediumborr $_{\text {b }}$ & $\begin{array}{c}-2.078 * * * \\
(0.658)\end{array}$ & $\begin{array}{c}0.186 \\
(0.116)\end{array}$ & $\begin{array}{c}0.552 * * * \\
(0.172)\end{array}$ & $\begin{array}{c}-0.342 * * \\
(0.170)\end{array}$ \\
\hline$N I L P j, n-1$ & $\begin{array}{c}0.650 * * \\
(0.327)\end{array}$ & $\begin{array}{c}-0.395 * * * \\
(0.083)\end{array}$ & $\begin{array}{c}-0.365 * * * \\
(0.085)\end{array}$ & $\begin{array}{c}1.034 * * * \\
(0.198)\end{array}$ \\
\hline$N I L P j, n-1 \times$ Majorlend & $\begin{array}{c}-0.666^{* *} \\
(0.326)\end{array}$ & $\begin{array}{c}0.287 * * * \\
(0.083)\end{array}$ & $\begin{array}{c}0.258 * * * \\
(0.084)\end{array}$ & $\begin{array}{c}-1.248 * * * \\
(0.257)\end{array}$ \\
\hline$N I L P j, n-1 \times \mathrm{Big}_{\mathrm{lend}}$ & $\begin{array}{c}-0.666^{* *} \\
(0.328)\end{array}$ & $\begin{array}{c}0.345^{* * *} \\
(0.079)\end{array}$ & $\begin{array}{c}0.321 * * * \\
(0.084)\end{array}$ & $\begin{array}{c}-1.136^{* * *} \\
(0.208)\end{array}$ \\
\hline$N I L P j, n-1 \times$ Medium lend $_{\text {l }}$ & $\begin{array}{c}-0.776^{* *} \\
(0.335)\end{array}$ & $\begin{array}{c}0.291 * * * \\
(0.077)\end{array}$ & $\begin{array}{c}0.334 * * * \\
(0.082)\end{array}$ & $\begin{array}{c}-0.687 * * * \\
(0.199)\end{array}$ \\
\hline BidWeighti,j,t(n) & $\begin{array}{c}-0.009 * * * \\
(0.001)\end{array}$ & $\begin{array}{c}-0.028 * * * \\
(0.002)\end{array}$ & $\begin{array}{c}-0.031 * * * \\
(0.002)\end{array}$ & $\begin{array}{c}-0.058 * * * \\
(0.006)\end{array}$ \\
\hline Intrai, $j$ & $\begin{array}{c}-0.296 * * * \\
(0.087)\end{array}$ & $\begin{array}{c}-0.435^{* *} \\
(0.200)\end{array}$ & $\begin{array}{c}-0.518 * * * \\
(0.190)\end{array}$ & $\begin{array}{c}-0.611 \\
(1.193)\end{array}$ \\
\hline Constant & $\begin{array}{c}234.419 * * * \\
(0.270)\end{array}$ & $\begin{array}{c}426.869 * * * \\
(2.213)\end{array}$ & $\begin{array}{c}427.303 * * * \\
(2.205)\end{array}$ & $\begin{array}{c}407.060 * * * \\
(6.227)\end{array}$ \\
\hline $\begin{array}{l}\mathrm{N} \text { of Clusters (Borrowers) } \\
\text { Borrower/Day/Lender FEs } \\
\text { Observations } \\
\text { R-squared }\end{array}$ & $\begin{array}{c}154 \\
\text { Yes/Yes/No } \\
140,418 \\
0.994\end{array}$ & $\begin{array}{c}140 \\
\text { Yes/Yes/No } \\
84,521 \\
0.828 \\
\end{array}$ & $\begin{array}{c}141 \\
\text { Yes/Yes/No } \\
89,487 \\
0.807\end{array}$ & $\begin{array}{c}103 \\
\text { Yes/Yes/No } \\
26,812 \\
0.993\end{array}$ \\
\hline \multicolumn{5}{|c|}{ p-values } \\
\hline 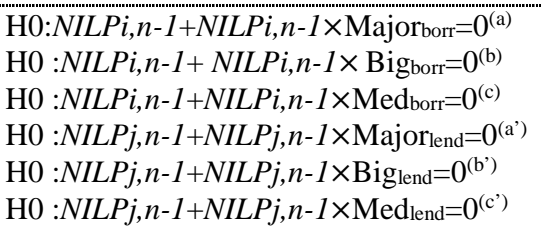 & $\begin{array}{c}0.255 \\
0.0322 \\
0 \\
0.0483 \\
0.223 \\
4.44 e-05\end{array}$ & $\begin{array}{c}0.167 \\
0.00994 \\
2.71 e-06 \\
4.57 e-06 \\
0.0845 \\
0.0359\end{array}$ & $\begin{array}{l}0.187 \\
0.0144 \\
3.22 e-05 \\
2.70 e-05 \\
0.161 \\
0.502\end{array}$ & $\begin{array}{c}0.875 \\
0.0772 \\
0.874 \\
0.121 \\
0.303 \\
0.000196\end{array}$ \\
\hline $\begin{array}{l}\text { (1) Regression using pre-crisis subsample: } \\
\text { 14.09.2008; (3) Regression using turmoil s } \\
\text { Regression using FRFA MRO period subs } \\
\text { LTROs). } \\
\text { Coefficients for Borrower and Date fixed e } \\
\text { clustered at borrower level. } \\
\text { *** Statistical significance at } 1 \% \text { level; ** } \\
\text { (a), (b), (c) p-values of F-statistics testing t } \\
\text { (a'), (b'), (c') idem for NILPj, }-1+N I L P j, r\end{array}$ & $\begin{array}{l}6 \text { to } 08.08 .200 \\
\text { included Lehn } \\
10.2008 \text { (anno } \\
\text { not reported. S } \\
* \text { Idem, } 10 \% \\
\text { sis that coeffi } \\
\text { d }=0 \text {. }\end{array}$ & $\begin{array}{l}\text { gression using } \\
\text { the FRFA MR } \\
\text { of FRFA MR } \\
\text { rrors reported } \\
P i, n-l+N I L P i\end{array}$ & $\begin{array}{l}\text { bsample before } \\
.2009 \text { (announ } \\
\text { sis are heterosk } \\
\text { orr }=0 \text {. }\end{array}$ & $\begin{array}{l}\text { n: } 09.08 .2007 \text { to } \\
07.10 .2008 ;(4) \\
\text { of FRFA } 1 \text { year } \\
\text { ity robust and }\end{array}$ \\
\hline
\end{tabular}

Moreover, the results from the t-tests displayed at the bottom of Table 5 indicate that only major banks never pay a significant liquidity premium, even during the crisis. On the contrary, large and medium banks pay a significant liquidity premium both before and during the crisis. It is lower than the one paid by small banks before the crisis but, interestingly, it becomes larger during the crisis and much larger after Lehman's collapse: the liquidity risk is considered more serious for larger banks after the onset of the crisis. 
Table C: Detailed Statistics of NILP for lenders and borrowers by size

\begin{tabular}{|c|c|c|c|c|c|c|c|c|c|c|c|}
\hline Variables & Size & mean & sd & $\min$ & $\max$ & p25 & p50 & p75 & p90 & iqr & $\mathbf{N}$ \\
\hline \multirow{5}{*}{ 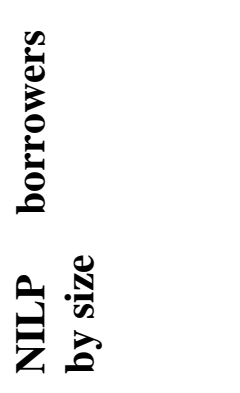 } & Major & 3.66 & 4.41 & $\begin{array}{l}- \\
31.30\end{array}$ & 35.57 & 1.12 & 3.73 & 6.25 & 8.25 & 5.13 & 38459 \\
\hline & Big $_{\text {borr }}$ & 2.57 & 2.66 & $\begin{array}{l}- \\
13.36\end{array}$ & 31.05 & 1.22 & 2.36 & 3.56 & 5.21 & 2.34 & 67257 \\
\hline & Mediumborr $_{\text {ber }}$ & 1.39 & 2.34 & -7.11 & 19.98 & 0.19 & 0.65 & 1.79 & 3.79 & 1.60 & 137628 \\
\hline & Small $_{\text {borr }}$ & 0.55 & 1.49 & -5.45 & 16.04 & 0.05 & 0.16 & 0.38 & 1.33 & 0.34 & 19637 \\
\hline & Total $_{\text {borr }}$ & 1.96 & 2.92 & $\begin{array}{l}- \\
31.30\end{array}$ & 35.57 & 0.24 & 1.11 & 3.02 & 5.34 & 2.78 & 262981 \\
\hline \multirow{5}{*}{ 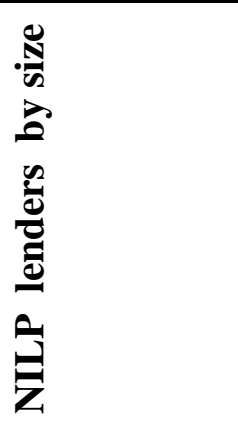 } & Majorlend & -3.05 & 4.20 & $\begin{array}{l}- \\
31.30\end{array}$ & 28.25 & -5.21 & -2.97 & -1.00 & 1.59 & 4.21 & 31050 \\
\hline & Biglend $_{\text {le }}$ & -2.10 & 2.81 & $\begin{array}{l}- \\
19.71\end{array}$ & 27.43 & -3.28 & -1.74 & -0.58 & 0.65 & 2.70 & 38629 \\
\hline & Mediumlend $_{\text {le }}$ & -0.70 & 0.95 & $\begin{array}{l}- \\
11.74\end{array}$ & 19.98 & -1.09 & -0.55 & -0.22 & 0.03 & 0.87 & 148704 \\
\hline & Small $_{\text {lend }}$ & -0.29 & 0.75 & -7.14 & 16.04 & -0.44 & -0.19 & -0.07 & -0.01 & 0.36 & 42177 \\
\hline & Total lend $_{\text {le }}$ & -1.12 & 2.16 & $\begin{array}{l}- \\
31.30\end{array}$ & 28.25 & -1.47 & -0.60 & -0.18 & 0.09 & 1.30 & 260560 \\
\hline
\end{tabular}


The influence of lenders' liquidity position is also affected by their size in a way that changes during the crisis. Recall that a negative sign of $N I L P J, n-1$ is interpreted as evidence of a hoarding behavior because it means that liquidity-long banks charge a premium when they lend money to liquidity-short ones. The t-tests at the bottom of Table 5 show that only major and medium banks have a significant negative sign of NILPj, $n-1$ before the crisis. In that period, small banks do not hoard. On the contrary, banks of any size hoard in the turmoil period before Lehman's collapse, but larger banks hoard less than the small ones because they charge a much smaller premium when they are liquidity-long in the previous MRO week. Only the small and the major ones keep a significant hoarding premium after Lehman's collapse. Overall, larger banks hoard both before and during the crisis, but they may do so for different motives: short-squeezing before the crisis and precautionary hoarding during the crisis. Small banks do not hoard before the crisis and only charge a positive premium when they are liquidity-short.

\subsection{The individual liquidity position effect and the distance from the end-of-RMP}

Within the official reserve maintenance period, European banks have to fulfill reserve requirements based on their previous month balance sheets. Thus, each bank knows in advance the average level of reserves that it should keep at the end of each day to smoothly satisfy reserve requirements. However, banks have the possibility to deviate from their daily required reserve targets as what matters is the average of their end of day reserves throughout the entire RMP. They may keep more than the daily required target on their reserve accounts at the beginning of the RMP and less at the end (front-loading), or inversely they may balance their beginning-of-RMP reserve shortage only at the end of the RMP (back-loading).

In normal times, when the i-b market is theoretically frictionless and the usage of standing facilities is not perceived as a bad signal, bank's choice of belonging to the back- or front- loading group depends mainly on the path of its individual liquidity shocks which in its turn is related to bank's specific activity, size etc. Thus, when the back- and front- loading groups are "liquidity shock" driven the overall liquidity needs tend to remain close to the 'benchmark' ${ }^{17}$ (just sufficient) level, as it is hard to imagine the whole system simultaneously receiving positive and negative shocks (see Kempa 2008). However during the crisis when the interbank market frictions increased and the recourse to the borrowing facility became stigmatizing, European banks' massively preferred to satisfy reserve requirement early in the RMP as back loading turned to be too costly. Under the neutral monetary policy implementation this "preference" driven reserve fulfillment menaced interbank rates to deviate considerably from the target rate and thus made the ECB providing more than the 'benchmark' at the beginning of the RMP and reabsorb it farther by the end of the period.

We recall that our NILP variable is computed for one MRO week whatever the distance of this later from the end-of-the RMP. Thus, in the Table 6 below we provide results from an additional specification which permits us to compare the sensibility of interbank rates to individual liquidity positions of the beginning to the ones of the end of the RMP. We use two

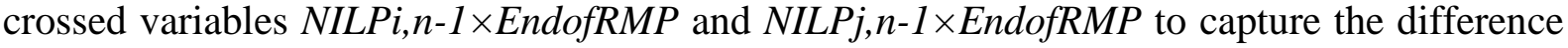
in the impact of the end-of-RMP positions. The variable EndofRMP is a dummy that is equal to 1 if the given $(\mathrm{n}-1)^{\text {th }} \mathrm{MRO}$ week is the last or the before last week of the RMP ${ }^{18}$.

The positive and significant coefficient of NILPi,n-1×EndofRMP in Table 6 column 1 shows that before the crisis the liquidity shortage premium for borrowers was approximately three times more important at the end of the RMP (back- loading) $(0.041+0,079)$ than at the

\footnotetext{
${ }^{17}$ Benchmark allotment was the expression to design the liquidity amount computed as the sum of the expected changes in autonomous factors and banks' remaining reserve requirements.

${ }^{18}$ Depending on the length of the RMP, the number of MRO weeks per RMP varies from 3 to 6 (most often 4-5)
} 
beginning of the RMP (front-loading). This seems quite natural as the probability of using standing facilities increase if the bank waits the end of the RMP to average reserves. However, we observe that during the crisis (see Table 6, column 2 and 3) the difference between the impacts of borrowers' end-of-RMP and beginning-of-RMP positions on rates is smaller compared to the pre-crisis phase (Table 6, column 2 and 3). We explain this fact by the massive front-loading preferences that characterized banks in the Eurosystem at that period. The number of banks waiting to adjust reserves at the end of the RMP being considerably smaller made the end-of-RMP borrower's interbank position at least as important as the beginning-of-RMP one.

Table 6 : Specification with liquidity position and EndofRMP interaction terms

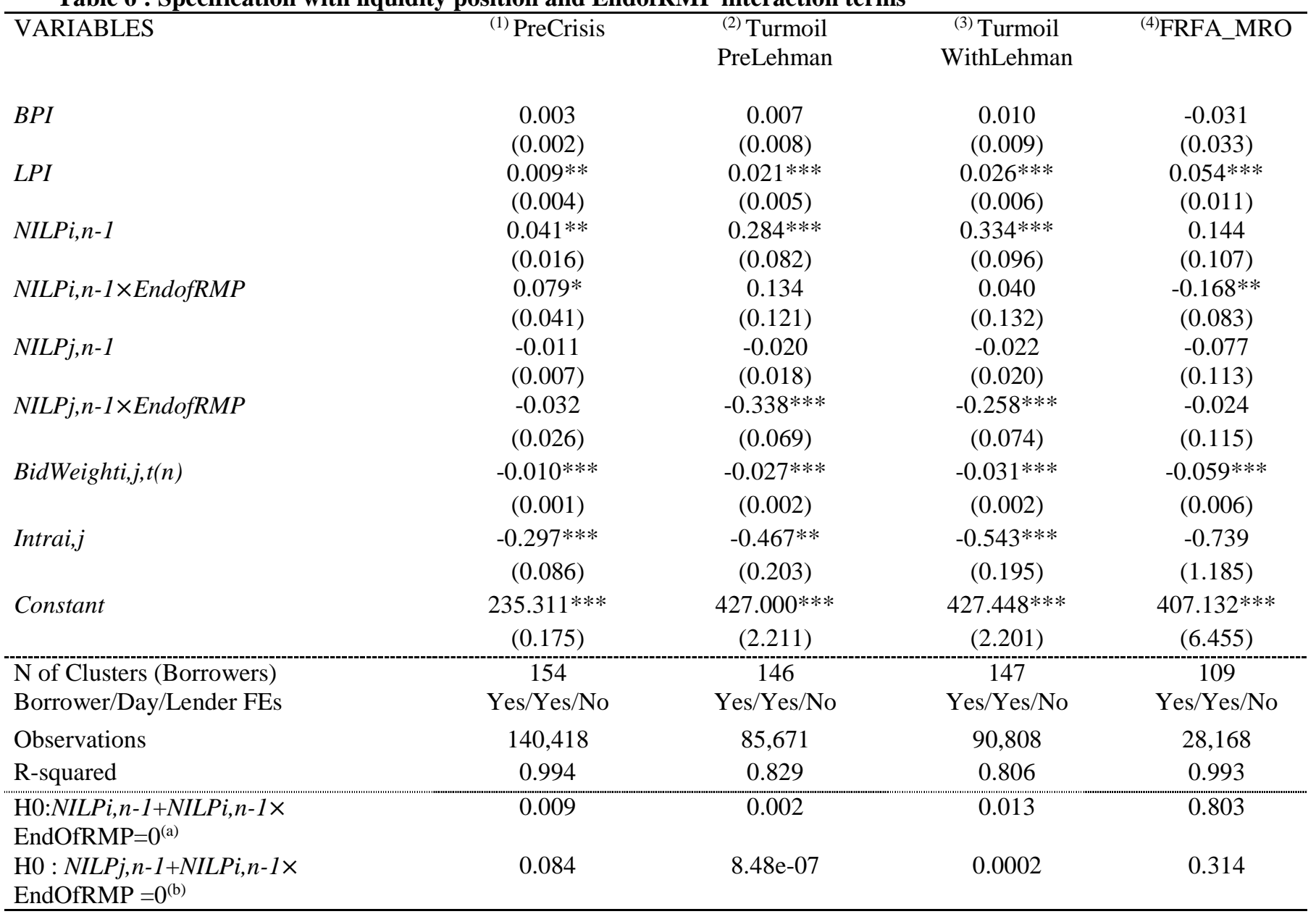

(1) Regression using pre-crisis subsample: 02.01.2006 to 08.08.2007 included

(2) Regression using turmoil subsample before Lehman: 09.08.2007 to 14.09.2008

(3) Regression using turmoil subsample included Lehman, until the FRFA MRO announcement: 09.08.2007 to 07.10.2008

(4) Regression using FRFA MRO period subsample: 08.10.2008 (announcement of FRFA MRO) to 07.05.2009 (announcement of FRFA 1 year LTROs).

Coefficients for Borrower and Date fixed effects are not reported

Standard errors reported in parenthesis are heteroskedasticity robust and clustered at borrower level.

$* * *$ Statistical significance at $1 \%$ level

** Idem, 5\%

* Idem, $10 \%$

(a) $\mathrm{p}$-values of F-statistics testing the hypothesis that coefficient $N I L P i, n-1+N I L P i, n-1 \times$ EndOfRMP $=0$

(b) idem for $N I L P j, n-1+N I L P i, n-1 \times$ EndOfRMP $=0$ 
Regarding the impact of the liquidity position of lenders, the evolution of the level and significance of NILPj,n-1×endofRMP (Table 6 column 2 and 3) during the crisis reveals that liquidity long banks were especially reluctant to lend in the last weeks of the RMP. This endof-RMP specific liquidity hoarding during the crisis could explain the massive front-loading strategy failover and changes in the operational framework of the ECB regarding the allocation of liquidity throughout the RMP.

\subsection{Addressing outliers and selection issues}

Some banks trade more infrequently than others and may create artificial interest rate heterogeneity. Moreover, a selection bias may be generated by the fact that some banks leave e-MID after the onset of the crisis whereas some others enter the market on the contrary. Table 7 below displays the results of regressions implemented on a sample of banks that trade on e-MID in every sub-period and frequently enough. More precisely, we excluded those that entered or leaved the market during one of the four sub-periods as well as those that traded in less than $10 \%$ of the operational days. Although the sample loses between 16 and 57 banks depending on the sub-period, the results are not changed. In particular, the impact of lenders' and borrowers' liquidity positions displays the same features as in the full sample regressions. 
Table 7: Robustness check $^{\S}$ of the basic specification (Table 3)

\begin{tabular}{|c|c|c|c|c|c|}
\hline & VARIABLES & (1)PreCrisis & ${ }^{(2)}$ TurmoilPreLehman & (3)TurmoilWithLehman & ${ }^{(4)}$ FRFA_MRO \\
\hline \multirow{2}{*}{\multicolumn{2}{|c|}{ BPI36 }} & $0.009 * * *$ & 0.006 & 0.007 & -0.041 \\
\hline & & $(0.003)$ & $(0.007)$ & $(0.009)$ & $(0.034)$ \\
\hline \multirow{2}{*}{\multicolumn{2}{|c|}{ LPI36 }} & $0.015 *$ & $0.027 * * *$ & $0.035 * * *$ & $0.050 * * *$ \\
\hline & & $(0.008)$ & $(0.007)$ & $(0.008)$ & $(0.011)$ \\
\hline \multirow{2}{*}{\multicolumn{2}{|c|}{$N I L P i, n-1$}} & $0.111 * * *$ & $0.367 * * *$ & $0.387 * * *$ & 0.095 \\
\hline & & $(0.042)$ & $(0.097)$ & $(0.106)$ & $(0.104)$ \\
\hline \multirow{2}{*}{\multicolumn{2}{|c|}{$N I L P j, n-1$}} & $-0.036 * * *$ & $-0.089 * * *$ & $-0.084 * * *$ & -0.120 \\
\hline & & $(0.014)$ & $(0.027)$ & $(0.029)$ & $(0.111)$ \\
\hline \multirow{2}{*}{\multicolumn{2}{|c|}{ BidWeighti,j,t(n) }} & $-0.010 * * *$ & $-0.027 * * *$ & $-0.030 * * *$ & $-0.054 * * *$ \\
\hline & & $(0.001)$ & $(0.002)$ & $(0.002)$ & $(0.006)$ \\
\hline \multirow{2}{*}{\multicolumn{2}{|c|}{ Intrai,j }} & $-0.318 * *$ & -0.371 & $-0.524^{*}$ & -0.626 \\
\hline & & $(0.127)$ & $(0.290)$ & $(0.288)$ & $(1.262)$ \\
\hline \multirow{2}{*}{\multicolumn{2}{|c|}{ Constant }} & $235.098 * * *$ & $431.557 * * *$ & $431.583 * * *$ & $426.742 * * *$ \\
\hline & & $(0.236)$ & $(2.395)$ & $(2.405)$ & $(5.886)$ \\
\hline & $\mathrm{N}$ of Clusters (Borrowers) & 97 & 100 & 100 & 93 \\
\hline & Borrower/Day/Lender & Yes/Yes/No & Yes/Yes/No & Yes/Yes/No & Yes/Yes/No \\
\hline & \multicolumn{5}{|l|}{ FEs } \\
\hline & Observations & 82,539 & 74,012 & 78,558 & 24,846 \\
\hline & R-squared & 0.994 & 0.833 & 0.810 & 0.993 \\
\hline & \multicolumn{5}{|c|}{$\begin{array}{l}\S \text { Both Buyers' and Sellers' panel is balanced within all } 4 \text { periods. Simultaneously, we have restricted both panels to active participants only, i.e. } \\
\text { dropped buyers and sellers who had traded within less than the } 10^{\text {th }} \text { percentile of operational days in each subsample. }\end{array}$} \\
\hline (5) & \multicolumn{5}{|c|}{ Regression using pre-crisis subsample: 02.01 .2006 to 08.08 .2007 included. } \\
\hline (6) & \multicolumn{5}{|c|}{ Regression using turmoil subsample before Lehman: 09.08.2007 to 14.09.2008. } \\
\hline (7) & \multicolumn{5}{|c|}{ Regression using turmoil subsample included Lehman, until the FRFA MRO announcement: 09.08 .2007 to 07.10.2008. } \\
\hline (8) & \multirow{2}{*}{\multicolumn{5}{|c|}{$\begin{array}{l}\text { Regression using FRFA MRO period subsample: } 08.10 .2008 \text { (announcement of FRFA MRO) to } 07.05 .2009 \text { (announcement of FRFA } 1 \text { year LTROs). } \\
\text { Coefficients for Borrower and Date fixed effects are not reported. }\end{array}$}} \\
\hline & & & & & \\
\hline & \multicolumn{5}{|c|}{$\begin{array}{l}\text { Standard errors reported in parenthesis are heteroskedasticity robust and clustered at borrower level. } \\
* * * \text { Statistical significance at } 1 \% \text { level. }\end{array}$} \\
\hline & \multicolumn{5}{|l|}{$* *$ Idem, $5 \%$. } \\
\hline & \multicolumn{5}{|l|}{ * Idem, $10 \%$. } \\
\hline
\end{tabular}




\section{Conclusions}

We studied at an individual level the price that banks pay for liquidity, as measured by overnight interest rates on the e-MID transparent trading platform. Using data from both before and within turmoil periods, we provided evidence that a borrower's and lender's liquidity positions influence this price both before and during the turmoil: borrowers that are liquidity-short in the week before they borrow pay a positive premium, and lenders that are liquidity-long in the week before they lend charge a positive premium. We interpret the former finding as evidence of a funding liquidity risk premium and the latter as evidence of liquidity hoarding. The liquidity premium disappears after the ECB has launched its full allotment policy in October 2008. This effect is robust to measure and sample variations.

We also assessed whether these liquidity effects were specific to particular types of banks or due to the period of reserve maintenance periods in the Euro system. We found that dealer banks paid a liquidity premium that was twice that paid by non-dealer banks in the crisis sub-periods and that only non-dealer banks charged a premium when they were liquidity-long. Regarding heterogeneity of this liquidity effect across sizes, we found that small banks paid the largest liquidity shortage premium before the crisis and that only major banks never paid a significant liquidity premium even during the crisis. On the contrary, large and medium banks paid a significant liquidity premium both before and during the crisis. This premium is lower than the one paid by small banks before the crisis but, interestingly, it becomes larger during the crisis and much larger after Lehman's collapse. Only major and medium banks have a significant negative sign of the liquidity position variable before the crisis meaning that, in that period, small banks do not hoard. On the contrary, banks of any size hoard in the turmoil period before Lehman's collapse, but larger banks hoard less than the small ones because they charge a much smaller premium when they are liquidity-long in the previous MRO week. Only the small and major banks keep a significant hoarding premium after Lehman's collapse. Finally, we found an end-of-RMP supplementary premium for liquidity-short banks before the crisis but it is no longer significant during the crisis. The increasing premium charged by liquidity-long banks during the crisis is significant and strong only in the last weeks of the RMP. These findings are in line with the changes in the reserve fulfillment preferences of banks throughout the RMP during the crisis.

As far as we know, these results are new to the literature on the individual rates paid by banks for liquidity because most previous cross-sectional studies on the funding liquidity risk focused on the primary money market and therefore examined banks behavior during the auctions organized by central banks for their main refinancing operations. Only one other cross-sectional study on the secondary Sterling money market by Acharya and Merrouche (2013) provides evidence of a funding liquidity risk because they find that individual unsecured overnight spreads vary significantly with the liquidity held by other banks (but not with the own bank liquidity endowment). We obtain different results for the Euro system because both the own liquidity position of borrowers and the liquidity situation of lenders appear to influence significantly the individual overnight rates in our estimations.

The political implications of such funding liquidity risk premiums are still to be analyzed, but we think that these problems could have worsened substantially if central banks had not decided to allot unlimited amounts of liquidity at fixed rates. Therefore, the existence of a funding liquidity risk premium is at least a reminder that interbank markets do not always allocate liquidity with efficiency and sometimes need to be supported by the lender as a last resort. 


\section{APPENDIX A1: computing the net lending positions over full lagged Reserve Maintenance Periods.}

Table A1: Regressions with Net Lending Positions computed over full lagged Reserve Maintenance Periods

\begin{tabular}{|c|c|c|c|c|}
\hline VARIABLES & PreCrisis & $\begin{array}{c}\text { Turmoil } \\
\text { PreLehman }\end{array}$ & $\begin{array}{c}\text { Turmoil } \\
\text { WithLehman }\end{array}$ & FRFA_MRO \\
\hline BPI36 & $\begin{array}{l}0.004 * \\
(0.002)\end{array}$ & $\begin{array}{c}0.006 \\
(0.009)\end{array}$ & $\begin{array}{c}0.008 \\
(0.009)\end{array}$ & $\begin{array}{l}-0.026 \\
(0.030)\end{array}$ \\
\hline LPI36 & $\begin{array}{c}0.008 * * \\
(0.004)\end{array}$ & $\begin{array}{c}0.024 * * * \\
(0.007)\end{array}$ & $\begin{array}{c}0.029 * * * \\
(0.006)\end{array}$ & $\begin{array}{c}0.055 * * * \\
(0.011)\end{array}$ \\
\hline$N I L P P_{i, \text { laggedRMP }}$ & $\begin{array}{c}0.099 \\
(0.063)\end{array}$ & $\begin{array}{c}0.444 * * \\
(0.195)\end{array}$ & $\begin{array}{c}0.532 * * * \\
(0.162)\end{array}$ & $\begin{array}{l}-0.006 \\
(0.262)\end{array}$ \\
\hline$N I L P_{j, \text { laggedRMP }}$ & $\begin{array}{l}-0.012 \\
(0.008)\end{array}$ & $\begin{array}{c}-0.088 * * * \\
(0.030)\end{array}$ & $\begin{array}{c}-0.090 * * * \\
(0.032)\end{array}$ & $\begin{array}{c}0.030 \\
(0.118)\end{array}$ \\
\hline BidWeighti,j,t(n) & $\begin{array}{c}-0.010 * * * \\
(0.001)\end{array}$ & $\begin{array}{c}-0.028 * * * \\
(0.002)\end{array}$ & $\begin{array}{c}-0.032 * * * \\
(0.002)\end{array}$ & $\begin{array}{c}-0.059 * * * \\
(0.006)\end{array}$ \\
\hline Intrai,j & $\begin{array}{c}-0.314 * * * \\
(0.088)\end{array}$ & $\begin{array}{l}-0.368^{*} \\
(0.222)\end{array}$ & $\begin{array}{c}-0.447 * * \\
(0.211)\end{array}$ & $\begin{array}{l}-1.903 \\
(1.173)\end{array}$ \\
\hline Constant & $\begin{array}{c}234.579 * * \\
(0.171)\end{array}$ & $\begin{array}{c}426.424 * * * \\
(2.265)\end{array}$ & $\begin{array}{c}426.655^{* * * *} \\
(2.257)\end{array}$ & $\begin{array}{c}428.497 * * * \\
(5.903)\end{array}$ \\
\hline $\begin{array}{l}\text { Day/Borr } \\
\text { effects }\end{array}$ & Yes/Yes & Yes/Yes & Yes/Yes & Yes/Yes \\
\hline Observations & 138,485 & 86,875 & 92,055 & 28,991 \\
\hline R-squared & 0.994 & 0.825 & 0.803 & 0.993 \\
\hline
\end{tabular}

Robust standard errors in parentheses

$* * * \mathrm{p}<0.01, * * \mathrm{p}<0.05, * \mathrm{p}<0.1$

\section{Appendix A2}

\section{Test of an alternative measure of funding liquidity risk}

In the theoretical literature, some authors make a clear distinction between within day (early) and end-of-day (late) liquidity shocks (Välimäki (2003), Pérez-Quirós and RodríguezMendizábal (2006), Kempa (2006)). In their models, only late unexpected liquidity movements occurring after the interbank market closure generate the necessity to use standing facilities. Interbank trading is supposed to be the most natural means of offsetting early shocks. This assumption implies that the higher is the volatility of unexpected end-of-day shocks the higher is the probability of resorting to standing facilities, which is considered being a liquidity risk because interbank markets are supposed to be less costly. However, it is quite difficult to identify empirically late reserve adjustments because one needs to get information not only on reserve movements themselves, but also on reserve fulfillment and recourse to standing facilities at individual bank level. Cocco and al. (2009) managed to isolate the reserve movements that are not related to $\mathrm{i}-\mathrm{b}$ trades and used the standard deviation of the latter as an indicator of liquidity risk. Even if the variable appeared being nonsignificant for liquidity pricing they showed that it was still important for the emergence of substantial liquidity relationships. Brauning and Fecht (2013) used the standard deviation of daily reserve changes over bank's reserve requirement for the same purpose, without differentiating end-of-day shocks from within-day shocks. This volatility based liquidity risk variable appears to be significant for i-b liquidity pricing. Note that within the crisis period 
when i-b market's frictions emerged, standing facilities were no longer exclusively used for offsetting end-of-day shocks. Moreover, the reserve adjustment either by i-b markets or by standing facilities became penalizing and the volatility of daily reserve changes started generating higher funding costs.

We thus test another proxy to capture bank's liquidity risk. Our e-MID dataset does not provide us any information on bank's daily reserve movements but we can proxy these shocks by the daily net lending positions (lendings-borrowings) of our banks on e-MID. If bank's net daily lending position is positive then we consider that it has received a positive schock; if it is negative then the shock is supposed to be negative. For each bank we compute the standard deviation of their daily liquidity shocks within one RMP. We call this variable LIQURisk $k_{\text {laggedRMP }}$ and introduce the lagged value of this new liquidity measure in our regressions instead of the NILP variables originally used. The results are in the following Table.

Table A2 : liquidity risk measured by the volatility of daily lending positions

\begin{tabular}{|c|c|c|c|c|}
\hline VARIABLES & PreCrisis & $\begin{array}{c}\text { Turmoil } \\
\text { PreLehman }\end{array}$ & $\begin{array}{c}\text { Turmoil } \\
\text { WithLehman }\end{array}$ & FRFA_MRO \\
\hline BPI36 & $\begin{array}{c}0.002 \\
(0.002)\end{array}$ & $\begin{array}{c}0.002 \\
(0.008)\end{array}$ & $\begin{array}{c}0.003 \\
(0.009)\end{array}$ & $\begin{array}{l}-0.040 \\
(0.027)\end{array}$ \\
\hline LPI36 & $\begin{array}{c}0.011 * * \\
(0.004)\end{array}$ & $\begin{array}{c}0.033 * * * \\
(0.007)\end{array}$ & $\begin{array}{c}0.039 * * * \\
(0.007)\end{array}$ & $\begin{array}{c}0.056 * * * \\
(0.011)\end{array}$ \\
\hline LIQURisk $_{i, \text { laggedRMP }}$ & $\begin{array}{c}0.000 \\
(0.000)\end{array}$ & $\begin{array}{c}0.002 \\
(0.001)\end{array}$ & $\begin{array}{l}0.003^{*} \\
(0.002)\end{array}$ & $\begin{array}{l}0.022 * * \\
(0.009)\end{array}$ \\
\hline LIQURisk $_{j, \text { laggedRMP }}$ & $\begin{array}{c}0.000 * * * \\
(0.000)\end{array}$ & $\begin{array}{c}0.002 * * * \\
(0.000)\end{array}$ & $\begin{array}{c}0.002 * * * \\
(0.000)\end{array}$ & $\begin{array}{c}0.015 * * * \\
(0.002)\end{array}$ \\
\hline Bidweight $_{i, j, t(n)}$ & $\begin{array}{c}-0.010 * * * \\
(0.001)\end{array}$ & $\begin{array}{c}-0.028 * * * \\
(0.002)\end{array}$ & $\begin{array}{c}-0.032 * * * \\
(0.002)\end{array}$ & $\begin{array}{c}-0.058 * * * \\
(0.006)\end{array}$ \\
\hline Intrai,j & $\begin{array}{c}-0.233 * * \\
(0.090)\end{array}$ & $\begin{array}{l}-0.050 \\
(0.209)\end{array}$ & $\begin{array}{c}-0.092 \\
(0.208)\end{array}$ & $\begin{array}{c}-0.535 \\
(1.290)\end{array}$ \\
\hline Constant & $\begin{array}{r}234.430 * * * \\
(0.172)\end{array}$ & $\begin{array}{c}425.302 * * * \\
(2.393)\end{array}$ & $\begin{array}{c}425.278 * * * \\
(2.426)\end{array}$ & $\begin{array}{c}418.503 * * * \\
(5.789)\end{array}$ \\
\hline Observations & 136,217 & 85,943 & 90,997 & 28,411 \\
\hline R-squared & 0.994 & 0.826 & 0.804 & 0.993 \\
\hline
\end{tabular}

Robust standard errors in parentheses

$* * * \mathrm{p}<0.01, * * \mathrm{p}<0.05, * \mathrm{p}<0.1$

If we compare these results to those using NILP variables in the basic specification (Table 3), we see that the slight changes do not modify the interpretation regarding the liquidity risk effect. Whereas NILP variables had a significant impact both before and within crisis, the volatility of borrowers' liquidity position is significant only in the turmoil period including Lehman's failure and in the FRFA period. In both sub-periods, borrowers paid a premium if this volatility was high. The volatility of lenders' liquidity position is significant in all subperiods and we see that they required a premium for borrowing when their liquidity position volatility was high. The main difference regarding the impact of this volatility measure on liquidity pricing compared to the NILP variable appears in the fourth column of Table A2: the impact and significance of LIQURisklaggedRMP increases after the implementation of the FRFA primary allocation of liquidity. This fact casts some doubt on the effectiveness of the ECB's interventions to mitigate liquidity risk. 


\section{REFERENCES}

Acharya, V., Gromb, D., Yorulmazer, T., 2011. Imperfect competition in the interbank market for liquidity as a rationale for central banking.

Acharya, V.V., Merrouche, O., 2013. Precautionary hoarding of liquidity and interbank markets: evidence from the subprime crisis. Review of Finance 17, 107-160.

Acharya, V.V., Skeie, D., 2011. A model of liquidity hoarding and term premia in inter-bank markets. Journal of Monetary Economics 58, 436-447.

Affinito, M., 2012. Do interbank customer relationships exist? And how did they function in the crisis? Learning from Italy. Journal of Banking \& Finance 36, 3163-3184.

Affinito, M., 2013. Central bank refinancing, interbank markets, and the hypothesis of liquidity hoarding: evidence from a euro-area banking system. Interbank Markets, and the Hypothesis of Liquidity Hoarding: Evidence from a Euro-Area Banking System (December 31, 2012).

Afonso, G., Shin, H.S., 2011a. Precautionary demand and liquidity in payment systems. Journal of Money, Credit and Banking 43, 589-619.

Afonso, Gara, Anna Kovner, and Antoinette Schoar, 2011b. Stressed, Not Frozen: The Federal Funds Market in the Financial Crisis. The Journal of Finance 66.4 (2011): 1109-1139 Allen, F., Carletti, E., Gale, D., 2009. Interbank market liquidity and central bank intervention. Journal of Monetary Economics 56, 639-652.

Allen, F., Gale, D., 2000. Financial contagion. Journal of political economy 108, 1-33.

Angelini, P., Nobili, A., Picillo, C., 2011. The interbank market after August 2007: what has changed, and why? Journal of Money, Credit and Banking 43, 923-958.

Arciero, L., 2010. Extracting Information on the Interbank Market from Payment System Data. Bank of Italy Occasional Paper Mimeo.

Arciero, L., Heijmans, R., Heuver, R., Massarenti, M., Picillo, C., Vacirca, F., 2013. How to Measure the Unsecured Money Market? The Eurosystem's Implementation and Validation Using TARGET2 Data.

Beirne, J., 2012. The EONIA spread before and during the crisis of 2007-2009: the role of liquidity and credit risk. Journal of International Money and Finance 31, 534-551.

Bindseil, U., Nyborg, K.G., Strebulaev, I.A., 2009. Repo auctions and the market for liquidity. Journal of Money, Credit and banking 41, 1391-1421.

Borio, C., 2003. Towards a macroprudential framework for financial supervision and regulation? CESifo Economic Studies 49, 181-215.

Borio, C., Nelson, W., 2008. Monetary operations and the financial turmoil. BIS Quarterly Review, 31-46.

Braeuning, F., Fecht, F., 2013. Relationship Lending in the Interbank Market and the Price of Liquidity. mimeo. Free University Amsterdam.

Brunetti, C., Di Filippo, M., Harris, J.H., 2011. Effects of central bank intervention on the interbank market during the subprime crisis. Review of Financial Studies 24, 2053-2083.

Brunnermeier, M.K., Pedersen, L.H., 2009. Market liquidity and funding liquidity. Review of Financial studies 22, 2201-2238.

Caballero, R.J., Krishnamurthy, A., 2008. Collective risk management in a flight to quality episode. The Journal of Finance 63, 2195-2230.

Cameron, A.C., Gelbach, J.B., Miller, D.L., 2011. Robust inference with multiway clustering. Journal of Business \& Economic Statistics 29.

Cappelletti, G., De Socio, A., Guazzarotti, G., Mallucci, E., 2011. The impact of the financial crisis on inter-bank funding: evidence from italian balance sheet data. Bank of Italy Occasional Paper. 
Cassola, N., Holthausen, C., Duca, M.L., 2008. The 2007/2008 Turmoil: A Challenge for the Integration of the Euro Area Money Market?

Cassola, N., Huetl, M., 2010. The Euro overnight interbank market and ECB's liquidity management policy during tranquil and turbulent times. European Central Bank.

Cassola, N., Morana, C., 2012. Euro money market spreads during the 2007-? financial crisis. Journal of empirical finance 19, 548-557.

Chordia, T., Roll, R., Subrahmanyam, A., 2000. Commonality in liquidity. Journal of Financial Economics 56, 3-28.

Christensen, J.H., Lopez, J.A., Rudebusch, G.D., 2009. Do central bank liquidity facilities affect interbank lending rates? Federal Reserve Bank of San Francisco Working Paper 13.

Cocco, J.F., Gomes, F.J., Martins, N.C., 2009. Lending relationships in the interbank market. Journal of Financial Intermediation 18, 24-48.

Drehmann, M., Nikolaou, K., 2013. Funding liquidity risk: definition and measurement. Journal of Banking \& Finance 37, 2173-2182.

Eisenschmidt, J., Hirsch, A., Linzert, T., 2009. Bidding behaviour in the ECB's main refinancing operations during the financial crisis. European Central Bank.

Eisenschmidt, J., Tapking, J., 2009. Liquidity risk premia in unsecured interbank money markets. European Central Bank.

Fecht, F., Nyborg, K.G., Rocholl, J., 2011. The price of liquidity: The effects of market conditions and bank characteristics. Journal of Financial Economics 102, 344-362.

Flannery, M.J., 1996. Financial crises, payment system problems, and discount window lending. Journal of money, credit and banking, 804-824.

Flannery, M.J., Sorescu, S.M., 1996. Evidence of bank market discipline in subordinated debenture yields: 1983-1991. The Journal of Finance 51, 1347-1377.

Frank, N., Hesse, H., 2009. The effectiveness of central bank interventions during the first phase of the subprime crisis. International Monetary Fund.

Freixas, X., Holthausen, C., 2005. Interbank market integration under asymmetric information. Review of Financial Studies 18, 459-490.

Freixas, X., Jorge, J., 2008. The role of interbank markets in monetary policy: A model with rationing. Journal of Money, Credit and Banking 40, 1151-1176.

Furfine, C.H., 2001. Banks as Monitors of Other Banks: Evidence from the Overnight Federal Funds Market*. The Journal of Business 74, 33-57.

Gabrieli, S., 2012. Too-connected versus too-big-to-fail: banks' network centrality and overnight interest rates.

Gaspar, V., Pérez Quirós, G., Rodríguez Mendizábal, H., 2004. Interest rate determination in the interbank market.

Hauck, A., Neyer, U., 2010. The Euro Area Interbank Market and the Liquidity Management of the Eurosystem in the Financial Crisis. DICE discussion paper.

Heider, F., Hoerova, M., Holthausen, C., 2008. Liquidity hoarding and interbank market spreads: The role of counterparty risk. European Banking Center Dis\% cussion Paper.

Holmström, B., Tirole, J., 2011. Inside and Outside Liquidity. MIT Press Books 1.

Iori, G., Kapar, B., Olmo, J., 2012. The Cross-Section of Interbank Rates: A Nonparametric Empirical Investigation.

Iori, G., Kapar, B., Olmo, J., 2014. Bank Characteristics and the Interbank Money Market: A Distributional Approach.

Kempa, M., 2006. Money market volatility - a simulation study. Bank of Finland Discussion Paper (13).

Kempa, M., 2007. What determines commercial banks' demand for reserves in the interbank market? Suomen Pankki. 
McAndrews, J., Sarkar, A., Wang, Z., 2008. The effect of the term auction facility on the london inter-bank offered rate. Staff Report, Federal Reserve Bank of New York.

Michaud, F.-L., Upper, C., 2008. What drives interbank rates? Evidence from the Libor panel. BIS Quarterly Review 3, 47-58.

Nobili, S., 2009. Liquidity risk in money market spreads, ECB Workshop on Challenges to Monetary Policy Implementation beyond the Financial Market Turbulence. Citeseer.

Nyborg, K.G., Strebulaev, I.A., 2004. Multiple unit auctions and short squeezes. Review of Financial Studies 17, 545-580.

Pérez-Quirós, G., Rodríguez-Mendizábal, H., February 2006. The daily market for funds in europe:what has changed with the emu. Journal of Money, Credit and Banking 38 (1), 91118.

Petersen, M.A., 2009. Estimating standard errors in finance panel data sets: Comparing approaches. Review of financial studies 22, 435-480.

Poole, W., 1968. Commercial bank reserve management in a stochastic model: implications for monetary policy. The Journal of finance 23, 769-791.

Rochet, J.-C., Tirole, J., 1996a. Controlling risk in payment systems. Journal of Money, Credit and Banking, 832-862.

Rochet, J.-C., Tirole, J., 1996b. Interbank lending and systemic risk. Journal of Money, credit and Banking, 733-762.

Schwarz, K., Mind the gap: Disentangling credit and liquidity in risk spreads.

Schwarz, K., 2010. Mind the Gap: Disentangling Credit and Liquidity in Risk Spreads. Available at SSRN 1486240.

Soares, C., Rodrigues, P.M., 2013. Determinants of the EONIA spread and the financial crisis. The Manchester School 81, 82-110.

Strahan, P., 2008. Liquidity production in 21st century banking. National Bureau of Economic Research.

Taylor, J.B.W., John C A black swan in the money market. American Economic Journal: Macroeconomics 1.

Thompson, S.B., 2011. Simple formulas for standard errors that cluster by both firm and time. Journal of Financial Economics 99, 1-10.

Tirole, J., 2011. Illiquidity and All Its Friends. Journal of Economic Literature 49, 287-325.

Valimaki, T., 2008. Why the effective price for money exceeds the policy rate in the ECB tenders?

Välimäki, T.,2003.Fixed rate tenders and the overnight money market equilibrium. Ph.D. thesis, Helsinki School of Economics and Bank of Finland. 